\title{
西藏雅鲁藏布缝合带甲查拉组：晚白严世新特提斯 洋海沟沉积?
}

傅焓埔 ${ }^{1}$, 胡修棉 ${ }^{*}$, Erica M. CROUCH ${ }^{2}$, 安慰 ${ }^{1,3}$, 王建刚 ${ }^{4}$, Eduardo GARZANTI $^{5}$

1. 内生金属矿床成矿机制研究国家重点实验室, 南京大学地球科学与工程学院, 南京 210023;

2. GNS Science, PO Box 30368, Lower Hutt 5040, New Zealand;

3. 合肥工业大学资源与环境工程学院, 合肥 230009 ;

4. 中国科学院地质与地球物理研究所, 北京 100029 ;

5. Department of Earth and Environmental Sciences, Università di Milano-Bicocca, Milano 20126, Italy

* 通讯作者, E-mail: huxm@nju.edu.cn

收稿日期：2017-10-10; 收修改稿日期：2018-02-11; 接受日期：2018-05-07; 网络版发表日期：2018-07-18 国家杰出青年科学基金项目(批准号: 41525007)和国家自然科学基金项目(批准号: 41602115)资助

摘要雅鲁藏布缝合带记录了印度与亚洲板块汇聚、碰撞及碰撞后造山的信息. 甲查拉组位于雅鲁藏布缝合带 南侧, 自建组以来一直被认为是印度-亚洲大陆碰撞后前陆盆地的深水沉积, 物源来自其北侧亚洲大陆南缘的冈 底斯弧. 然而, 一个长期令人不解的问题是: 甲查拉组砂岩最年轻的碎屑锆石年龄为 $88 \mathrm{Ma}$, 考虑冈底斯弧晚白严 世-古近纪持续的岩浆活动, 如果地层时代是前人基于孢粉、沟鞭藻化石提出的古新世-早始新世(65 50Ma), 为何 砂岩中缺乏白严纪晚期-始新世早期(88 50Ma)的碎屑锆石? 针对这个问题，本次研究对江孜-萨迦地区的甲查拉 组开展了孢粉、沟鞭藻化石分析、岩石地层学、沉积学与物源分析等工作。两个不同实验室的分析处理都未获 得保存良好的孢粉、沟鞭藻化石; 甲查拉组与宗卓组呈断层接触, 岩石组合与沉积结构、构造指示海底扇沉积 环境; 碎屑组分、碎屑锆石 $\mathrm{U}-\mathrm{Pb}$ 年龄和 $\mathrm{Hf}$ 同位素指示甲查拉组的物源来自冈底斯弧和中拉萨地体, 最年轻的碎 屑锆石年龄为 $84 \mathrm{Ma}$. 综合考虑沉积环境、物源与大地构造位置, 在区域对比研究基础上, 本文认为甲查拉组的时 代很可能是晚白严世(88 84Ma), 代表了新特提斯洋向北俯冲阶段亚洲南缘的海沟沉积.

关键词物源分析, 海沟沉积, 晚白严世, 新特提斯洋俯冲, 雅鲁藏布缝合带, 中国西藏

\section{1 引言}

雅鲁藏布缝合带(图1)是印度与亚洲板块的构造 边界(Gansser, 1980), 其中和两侧的地质单元, 如蛇绿 岩套(Hébert等, 2012; Dai等，2013), 混杂岩(Cai等, 2011，2012；An等，2017), 碰撞后的砾岩带(Wang等,
2013；Ｌi等，2015; Leary等，2016), 日喀则弧前盆地 (Wang等, 2012; An等, 2014; Hu等, 2016a; Wang等, 2017), 印度大陆边缘盆地(Garzanti，1999; Najman等, 2010; Hu等2010, 2012; Garzanti和 Hu, 2015 ), 记录了从 新特提斯洋俯冲到印度-亚洲大陆初始碰撞以及喜马 拉雅隆升的信息.

\footnotetext{
中文引用格式: 傅焓埔, 胡修棉, Crouch E M, 安慰, 王建刚, Garzanti E. 2018. 西藏雅鲁藏布缝合带甲查拉组: 晚白严世新特提斯洋海沟沉积? 中国科学: 地球 科学, 48: 1275-1292, doi: 10.1360/N072017-00199

英文引用格式: Fu H P, Hu X M, Crouch E M, An W, Wang J G, Garzanti E. 2018. Upper Cretaceous trench deposits of the Neo-Tethyan subduction zone: Jiachala Formation from Yarlung Zangbo suture zone in Tibet, China. Science China Earth Sciences, 61: 1204-1220, https://doi.org/10.1007/s11430-0179223-5
} 


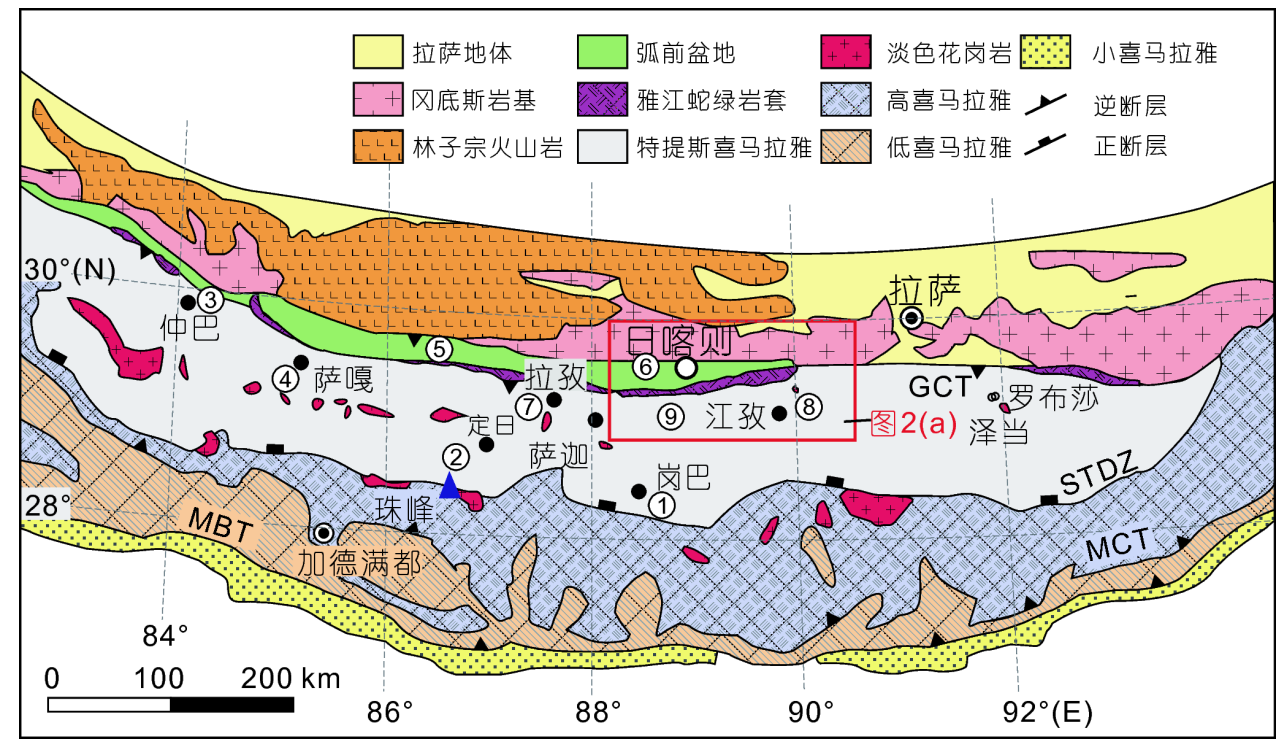

图 1 喜马拉雅地质简图(据潘桂棠等, 2004)

(1)和(2)示恩巴组和扎果组(Najman等, 2010; Hu等, 2012; Li等, 2015); (3)示曲下组和加拉孜组(Hu等, 2016a); (4)示桑单林组和者雅组(Wang等, 2011；DeCelles等, 2014; Wu等, 2014; Hu等, 2015); (5)示帕达那组(An等, 2014); (6)示昂仁组(An等, 2014); (7)示修康混杂岩(An等, 2017); (8)和9)示甲查拉组. GCT, 大反转逆冲断裂; STDZ, 藏南拆离系; MCT, 主中央逆冲断裂; MBT, 主边界逆冲断裂

甲查拉组位于雅鲁藏布缝合带南侧, 创名于江孜 县甲查拉山, 主要为一套厚层砂岩夹少量泥页岩地层 (李国彪等, 2004). 自建组以来, 许多学者对其进行了 研究，取得的主要认识包括：它是一套深水浊流沉积, 与下伏宗卓组沉积接触(李国彪等，2004；魏玉帅等， 2006; 蔡福龙等, 2008); 时代为古新世-早始新世(据矠 粉、沟鞭藻化石, 李国彪等, 2004); 物源主要来自亚洲 大陆的冈底斯弧(魏玉帅等, 2006; 蔡福龙等, 2008; Wu 等，2014). 基于这些认识，甲查拉组被认为是印度-亚 洲大陆初始碰撞后的前陆盆地沉积(李国彪等，2004; 蔡福龙等, 2008).

然而，前人对甲查拉组的认识存在一些令人迷惑 的地方. 甲查拉组的物源主要来自冈底斯弧(魏玉帅 等, 2006; 蔡福龙等, 2008; Wu等, 2014), 冈底斯弧在 晚白严世-古近纪持续活动( $\mathrm{Ji}$ 等，2009; Lee等，2009; Zhu等, 2011); 理论上讲，甲查拉组最年轻的碎屑锆石 年龄应与地层时代相近(Dickinson和Gehrels, 2009). 如 果地层时代是狍粉、沟鞭藻化石指示的古新世-早始 新世(65 50Ma)(李国彪等，2004), 为何最年轻的碎屑 锆石年龄为 $88 \mathrm{Ma}$ (蔡福龙等, $2013 ; \mathrm{Wu}$ 等, 2014)? 为了 查清甲查拉组的沉积-大地构造背景, 合理解释这一矛 盾, 特进行了一些深化研究, 包括: (1) 甲查拉组的地层 调查和沉积环境分析; (2) 甲查拉组的物源分析，包括
碎屑组分、碎屑锆石U-Pb年龄和Hf同位素; (3) 甲查 拉组狍粉、沟鞭藻化石分析. 基于这些研究结果, 本 文试图重新讨论甲查拉组的时代、大地构造性质及其 地质演化.

\section{2 区域地质背景}

从北向南，青藏高原南部主要由拉萨地体、雅鲁 藏布缝合带、特提斯喜马拉雅三个地质单元组成(图 1、2).

雅鲁藏布缝合带由雅鲁藏布蛇绿岩套、修康混杂 岩和碰撞后的砾岩带组成. 雅鲁藏布蛇绿岩套由地幔 橄榄岩、堆晶辉长岩、席状岩墙、枕状熔岩和含放射 虫硅质岩组成; 辉绿岩和辉长岩的锆石 $\mathrm{U}-\mathrm{Pb}$ 年龄、角 闪岩角闪石的 ${ }^{40} \mathrm{Ar}-{ }^{39} \mathrm{Ar}$ 年龄和含放射虫硅质岩的古生 物年龄将其时代约束为 $128 \sim 120 \mathrm{Ma}$ (Göpel等，1984; Ziabrev等，2003；Guilmette等，2009，2012；Hébert等， 2012; Dai等, 2013). 修康混杂岩是新特提斯洋俯冲和 印度-亚洲大陆碰撞两阶段的产物, 沿蛇绿岩套南侧分 布，由泥质基质混杂岩和少量的浊积岩组成(Cai等, 2012), 其中的砂岩岩块可以分为三组(An等, 2017): 第 一组来自印度被动大陆, 第二组来自新特提斯洋俯冲 时期的海沟沉积，第三组来自碰撞后的亚洲大陆. 碰 

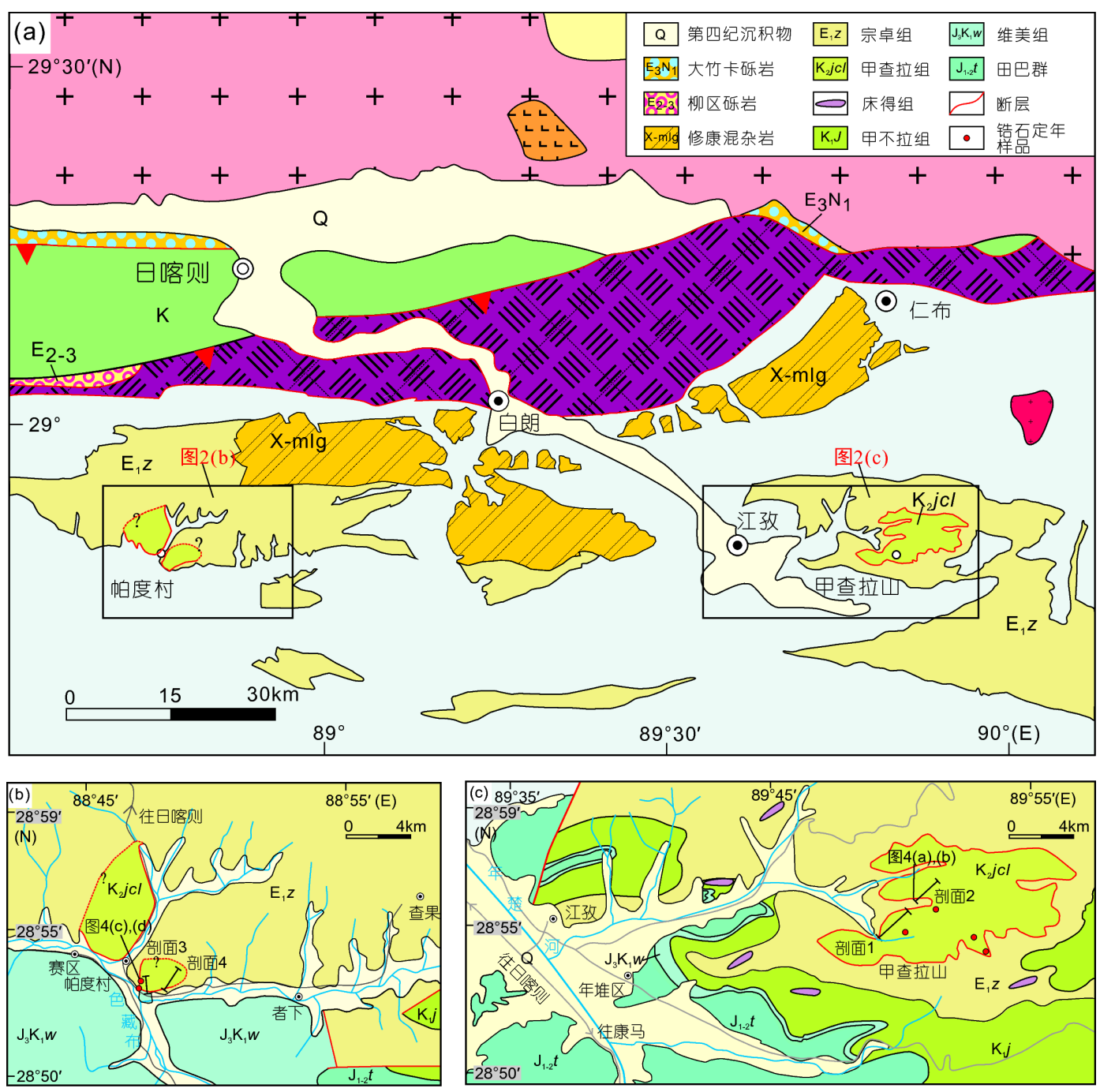

图 2 研究区位置和邻区地质单元概况(a)、萨迦县帕度村(b)和江孜县甲查拉山(c)地质示意图 (a) 据潘桂棠等(2004); (b)和(c)据万晓樵和刘文灿(2005) 、胡修棉等(2006)和实际观察. 图例同图1

撞后的砾岩带由北侧沿冈底斯南麓分布的秋乌组、大 竹卡组(冈仁波齐砾岩)和南侧沿雅鲁藏布蛇绿岩套分 布的柳区砾岩组成(Wang等, 2013; Li等，2015; Leary 等, 2016).

雅鲁藏布缝合带以北的拉萨地体根据基底和盖层 可以分为北、中、南三个地体. (1) 北拉萨地体: 以侏 罗纪-白严纪的沉积岩和火成岩为主(潘桂棠等，2006; Zhu等, 2009); (2) 中拉萨地体: 以石炭纪-二叠纪变沉 积岩和早侏罗世-晚白严世火山-沉积地层为主(Kapp 等, 2005; Zhu等, 2011), 中生代锆石的 $\varepsilon_{\mathrm{Hf}}(t)$ 以负值为主
(Chu等, 2006; 张宏飞等, 2007a; Zhu等, 2011); (3) 南拉 萨地体: 以晚三叠世-古近纪持续活动的冈底斯弧和白 严纪-古近纪的林子宗火山序列为主, 分布少量的晚三 叠世-白严纪沉积盖层(Schärer等, 1984; 潘桂棠等, 2006; Mo等, 2008; Wen等, 2008; Ji等, 2009; Lee等, 2009; Zhu等, 2008, 2013), 中生代锆石的 $\varepsilon_{\mathrm{Hf}}(t)$ 以正值为 主(Chu等, 2006; 李皓扬等, 2007; 张宏飞等, 2007b; Ji 等, 2009; Zhu等, 2009, 2011). 沿拉萨地体南缘出露的 日喀则弧前盆地从白严纪-古近纪持续接受冈底斯弧 为主的物质充填, 地层单元包括冲堆组、桑祖冈组、

1) 万晓樵, 刘文灿. 2005. 1:250000江孜县幅地质图. 北京: 中国地质调查局 
昂仁组、帕达那组、曲贝亚组、曲下组和加拉孜组 (Einsele等, 1994; Wu等, 2010; Wang等, 2012; An等, 2014; Orme等, 2015; Hu等, 2016a).

雅鲁藏布缝合带以南的特提斯喜马拉雅以吉隆康马断裂为界可以分为南、北两个亚带(Ratschbacher 等, 1994). 南亚带以古生代-始新世的浅水沉积为主 (Jadoul等, 1998; Garzanti，1999), 北亚带以中生代-古 近纪的深水沉积为主( $\mathrm{Li}$ 等, 2005).

\section{1 研究地区地层}

研究区位于特提斯喜马拉雅北亚带的江孜-萨迦 一带, 出露的地层包括维美组、甲不拉组、床得组和 宗卓组等. 维美组是Tithonian-Berriasian的深海下斜坡 沉积(李祥辉等, 2000; Li等, 2013). 甲不拉组是早白严 世-Coniacian的深海大陆斜坡-深海盆地沉积(李祥辉 等, 1999; 王成善等, 2000; Li等, 2005; 胡修棉等, 2006). 床得组是Santonian晚期-Maastrichtian的大洋红层(李 祥辉等, 1999; Hu等, 2005; Wang等, 2005; 胡修棉等, 2006; Chen等, 2011). 宗卓组是印度-亚洲大陆碰撞早 期(古新世末期-始新世早期)的海沟沉积, 由正常沉积 的基质、原地岩块和外来岩块组成, 砂岩岩块主要来 自亚洲大陆(萄新望, 1998; Liu和Aitchison, 2002; Cai 等, 2011; 孙高远等, 2011; Wu等, 2014; 胡修棉等, 2017a; 周博等, 2018).

\section{2 初始碰撞时间}

不同学者对印度-亚洲大陆初始碰撞采用的定义 不尽相同, 利用不同方法获得的结果差异也很大(胡修 棉等, 2017b). 多数学者采用印度北缘陆壳到达亚洲南 缘海沟的时间作为印度-亚洲大陆初始碰撞的时间 (Beck等, 1995; Hu等, 2012, 2016b). Hu等(2015)根据萨 嘎桑单林剖面深海浊积岩记录的物源变化(由印度物 源转变为亚洲物源), 将印度-亚洲大陆初始碰撞时代 精确限定为 $(59 \pm 1) \mathrm{Ma}$, 与其他多门学科的地质记录和 研究结果一致(Hu等, 2016b; 朱弟成等, 2017; 丁林等, 2017).

\section{3 分析方法}

本次研究实测 4 条剖面, 剖面 1 和剖面 2 位于江孜县 甲查拉山，与李国彪等(2004)、魏玉帅等(2006)和Wu
等(2014)的研究地点相同; 剖面3和剖面4位于萨迦县 帕度村, 为本次研究新发现的露头(图3). 岩相描述根 据Mutti和Ricci Lucchi(1978), Thornburg和Kulm (1987), Underwood和Moore (1995).

分别选取 8 件和 10 件泥页岩样品在新西兰地质与 核能研究有限公司(GNS)孢粉学实验室和中国科学院 南京地质古生物研究所进行孢粉、沟鞭藻化石分析处 理. 两个实验室分析处理的方法类似, GNS孢粉学实验 室分析处理的具体步骤为: 每件样品取 $41 \sim 49 \mathrm{~g}$ 干燥沉 积物, 用盐酸 (10\%)去钻、氢氟酸 $(50 \%)$ 去硅, 热盐酸 分散含氟凝胶, 然后进行重液分离(多铇酸钠, 比重2), 用超声波(15 30s)破碎有机质团块, 置于超声波盆清 洗 1 分钟, 过篮保留粒径大于 $6 \mu \mathrm{m}$ 的部分. 3 件样品 (16JCL27、16JCL38和16JCL40)还进行了舒尔茨氧化 并用氨溶液洗涤10 15 分钟, 来检测有机质中是否有额 外的狍粉. 最后将全部有机质残留物用甘油胶粘于玻 璃片, 供显微镜下观察.

选取 10 件砂岩样品进行碎屑统计, 每件样品根据 Gazzi-Dickinson法至少统计 400 个点(据Ingersoll等, 1984).7件砂岩样品(采样位置参见图2)通过碎样、淘 洗、磁选后在双目镜下挑选出锆石颗粒并固定在环氧 树脂靶上, 抛光至中心部位进行碎屑锆石 $\mathrm{U}-\mathrm{Pb}$ 定年. 每件样品测试60 80个点. 碎屑锆石 $\mathrm{U}-\mathrm{Pb}$ 定年在南京 大学内生金属矿床成矿机制研究国家重点实验室完 成. 所用仪器为连接New Wave UP213固体激光剥蚀系 统(LA)的Agilent 7500a 型等离子质谱仪(ICP-MS), 测 试方法据Jackson等(2004), 普通Pb校正据Andersen (2002), 年龄结果计算使用GLITTER4.4(van Achterbergh等, 2001). 年龄小于 $1000 \mathrm{Ma}$ 的颗粒采用 ${ }^{206} \mathrm{~Pb} /{ }^{238} \mathrm{U}$ 年龄, 年龄大于 $1000 \mathrm{Ma}$ 的颗粒则采用 ${ }^{207} \mathrm{~Pb} /{ }^{206} \mathrm{~Pb}$ 年龄, 选取年龄大于 $200 \mathrm{Ma}$ 且偏差小于 $10 \%$ 和年龄小于 $200 \mathrm{Ma}$ 且偏差小于 $20 \%$ 的数据进行讨论. 最后用Isoplot4.0(Ludwig，2011)计算加权平均年龄，绘制年龄 谱图.

选取U-Pb年龄小于 $250 \mathrm{Ma}$ 的碎屑锆石进行原位 $\mathrm{Hf}$ 同位素测试. 测试在南京大学内生金属矿床成矿机制 研究国家重点实验室完成. 所用仪器为安装GeoLas PLUS 193激光剥蚀系统(LA)的Neptune多接收等离子 质谱仪(MC-ICPMS). 实验激光束斑直径为 $35 \mu \mathrm{m}$, 频率 为 $8 \mathrm{~Hz}$, 能量为 $15.5 \mathrm{~J} / \mathrm{cm}^{2}$. Hf模式年龄 $\left(T_{\mathrm{DM}}\right)$ 和 $\varepsilon_{\mathrm{Hf}}(t)$ 计算 据Griffin等 $(2000) .{ }^{176} \mathrm{Lu}$ 衰变常数采用 $\lambda=1.867 \times 10^{-11}$ 

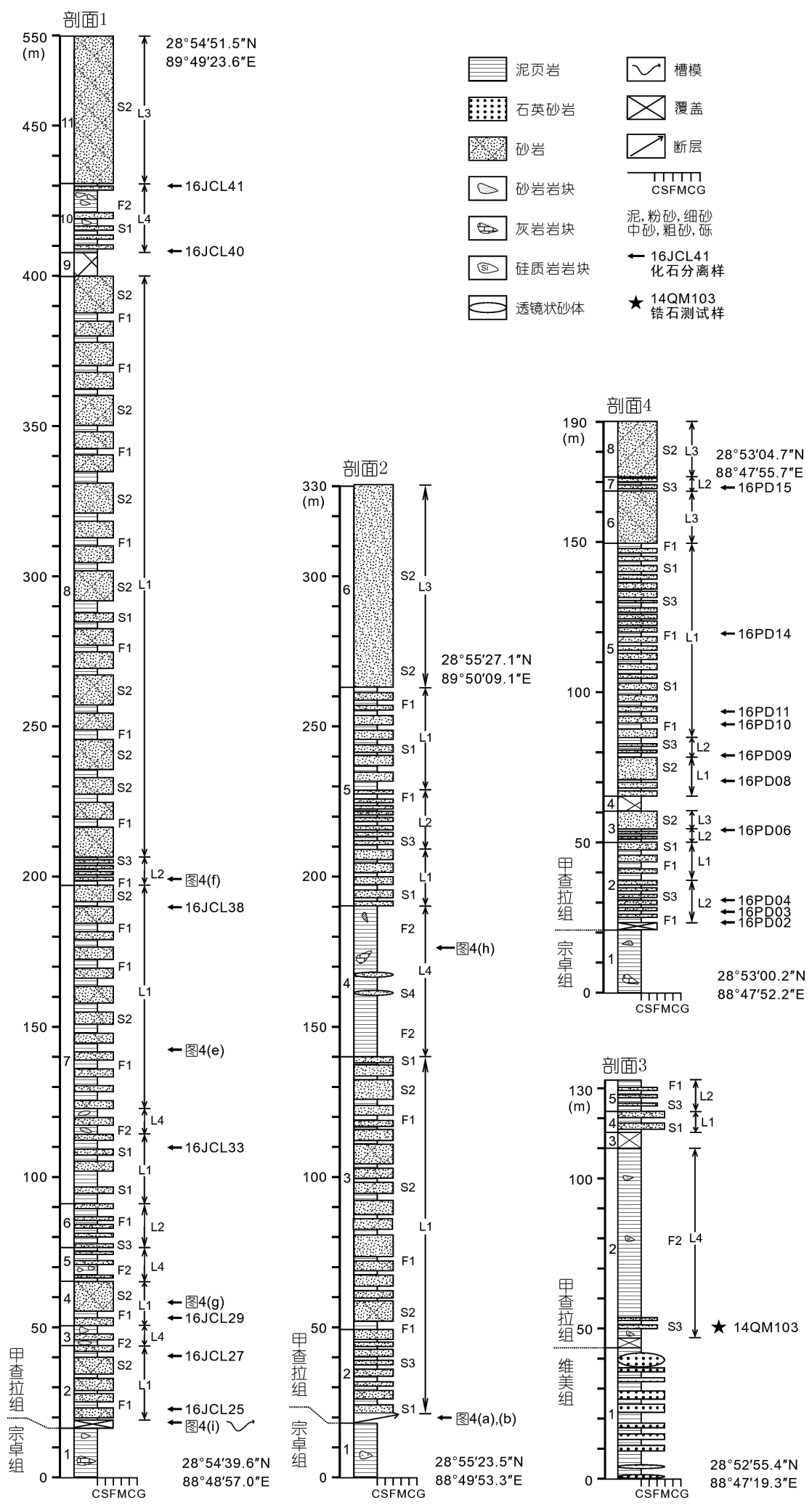

图 3 甲查拉组实测剖面柱状图

剖面位置参见图2, 岩相符号参见表1 
傅焓埔等: 西藏雅鲁藏布缝合带甲查拉组: 晚白严世新特提斯洋海沟沉积?

表 1 实测剖面的岩相划分(甲查拉组)与解释)

\begin{tabular}{ccc}
\hline 岩相 & 描述 & 沉积过程解释 \\
\hline $\mathrm{F} 1$ & 灰绿色、黑色页岩, 层厚 $5 \sim 15 \mathrm{~cm}$ & 低密度浊流沉积 \\
$\mathrm{F} 2$ & 灰黑色页岩夹灰岩、砂岩岩块, 页岩层变形严重 & 滑塌沉积 \\
$\mathrm{S} 1$ & 中-细粒砂岩, 分选差, 见槽模构造, 层厚 $0.2 \sim 2 \mathrm{~m}$ & 浊流沉积 \\
$\mathrm{S} 2$ & 大套中细粒砂岩, 分选差, 块状构造, 层厚大于 $2 \mathrm{~m}$ & 高密度浊流沉积 \\
$\mathrm{S} 3$ & 与页岩互层的薄层细粒砂岩, 分选差, 层厚小于 $0.2 \mathrm{~m}$ & 低密度浊流沉积 \\
$\mathrm{S} 4$ & 透镜体状砂岩, 层厚 $0.1 \sim 0.3 \mathrm{~m}$ & 水道沉积 \\
\hline
\end{tabular}

a) 岩相划分据Mutti和Ricci Lucchi(1978)、Thornburg和Kulm(1987)、Underwood和Moore(1995)

(Söderlund等，2004). 完整数据见附表 1 和 2 (网络版附 表1和2, http://earthen. scichina.com)

\section{4 分析结果}

\section{1 地层特征}

剖面1、剖面2和剖面4实测厚度分别为 550 、330 和 $190 \mathrm{~m}$, 出露的地层为宗卓组和甲查拉组; 剖面3实测 厚度为 $130 \mathrm{~m}$, 出露的地层为维美组和甲查拉组(图3). 在剖面2和帕度村(GPS: $\left.28^{\circ} 53^{\prime} 31.0^{\prime \prime} \mathrm{N} ， 88^{\circ} 46^{\prime} 41.7^{\prime \prime} \mathrm{E}\right)$ 两个地点观察到甲查拉组与宗卓组呈断层接触(图2, 4). 在剖面 2 , 甲查拉组是一套正常地层, 以中厚层砂岩 夹薄层页岩为主, 而宗卓组是一套混杂岩, 以页岩基质 夹砂岩、灰岩岩块为主; 两套地层的界线清晰, 宗卓组 页岩基质的倾角明显小于甲查拉组岩层倾角(图4a、 b). 在帕度村, 宗卓组为黑色页岩夹砂岩岩块, 甲查拉 组为中厚层砂岩, 两者岩性发生突变 (图4c、d).

\section{2 沉积环境}

本次研究划分出 4 个岩相带, 包含6种岩相(表1). 岩相带1(L1，在剖面1、剖面2、剖面3和剖面4中，厚 度分别为 $>200 、>200 、 20$ 和 $100 \mathrm{~m}$ ) 是甲查拉组的主体, 由岩相 $\mathrm{S} 1 、 \mathrm{~S} 2 、 \mathrm{~S} 3$ 和 $\mathrm{F} 1$ 组成，为中细粒砂岩夹灰绿 色、灰黑色页岩，页岩层侧向延伸较好，砂岩层厚 $0.1 \sim 3 \mathrm{~m}$, 砂岩与页岩的层厚比大于 3 (图4e), 砂岩多呈 块状构造，见槽模构造(图4i). 岩相带2(L2, 在剖面1、 剖面2、剖面3和剖面4中，厚度分别为20、20、10和 $60 \mathrm{~m})$ 由岩相 $\mathrm{S} 3$ 和 $\mathrm{F} 1$ 组成, 为细粒砂岩与灰绿色、灰黑 色页岩互层，页岩层侧向延伸好，砂岩层厚小于 $20 \mathrm{~cm}$, 砂岩与页岩的层厚比稍大于1(图4f). 岩相带3(L3, 在剖 面 1 、剖面 2 、剖面3和剖面4中，厚度分别为 $>200$ 、
$>200 、 0$ 和 $>50 \mathrm{~m}$ ) 由岩相 $\mathrm{S} 2$ 组成, 为巨厚层块状砂岩 (图4g). 岩相带4(L4, 在剖面1、剖面2、剖面3和剖面4 中, 厚度分别 $60 、 50 、 60$ 和 $0 \mathrm{~m}$ )由岩相 $\mathrm{S} 3 、 \mathrm{~S} 4$ 和 $\mathrm{F} 2$ 组 成，为灰绿色、灰黑色页岩夹砂岩、灰岩等岩块，偶 见透镜体状和薄层状细粒砂岩, 页岩层侧向延伸差, 部分变形强烈(图4h). 这些沉积特征表明甲查拉组为 浊流广泛发育的海底扇沉积.

\section{3 孢粉、沟鞭藻化石特征}

甲查拉组 18 件样品经两个不同实验室分析处理后 均未见保存良好的孢粉、沟鞭藻化石，可见陆源植物 碎片(包括三种：清晰的、暗-黑色的和降解的)、降解 的孢粉、无定型的有机质(AOM)和矿物颗粒(图5), 指 示其中的有机质经历了强烈的热变质作用.

\section{4 物源分析}

\subsection{1 碎屑组分}

甲查拉组的 10 件砂岩成分类似, 以岩屑质长石石 英砂岩-长石质岩屑石英砂岩为主(分类据Garzanti, 2016)，甲查拉山5件样品(14QM111、14QM113、 $14 \mathrm{QM} 115 、 14 \mathrm{QM} 116$ 和 $14 \mathrm{QM} 119)$ 的平均粒径为 $80 \sim 150 \mu \mathrm{m}$, 石英、长石和岩屑的比值为 $48: 30: 22$; 帕度 村5件样品(08JCL03、08JCL04、08JCL07、08JCL13 和 $08 \mathrm{JCL} 15)$ 的平均粒径为 $200 \sim 300 \mu \mathrm{m}$, 石英、长石和 岩屑的比值为 $63: 15: 22$. 石英以单晶石英为主(占总石 英的96 99\%), 岩屑以安山岩、流纹岩等中酸性火山 岩岩屑为主, 可见泥岩、粉砂岩和碳酸盐岩等沉积岩 岩屑以及变粉砂岩、千枚岩等变质岩岩屑(图6); 石 英、长石和岩屑的相对含量分别为 $41 \sim 73 \%$ 、 $8 \sim 35 \%$ 和 $18 \sim 28 \%$, 火山岩岩屑、沉积岩岩屑和变质岩岩屑的 相对含量分别为59 99\%、0 30\%和0 18\%(表2, 图7). 

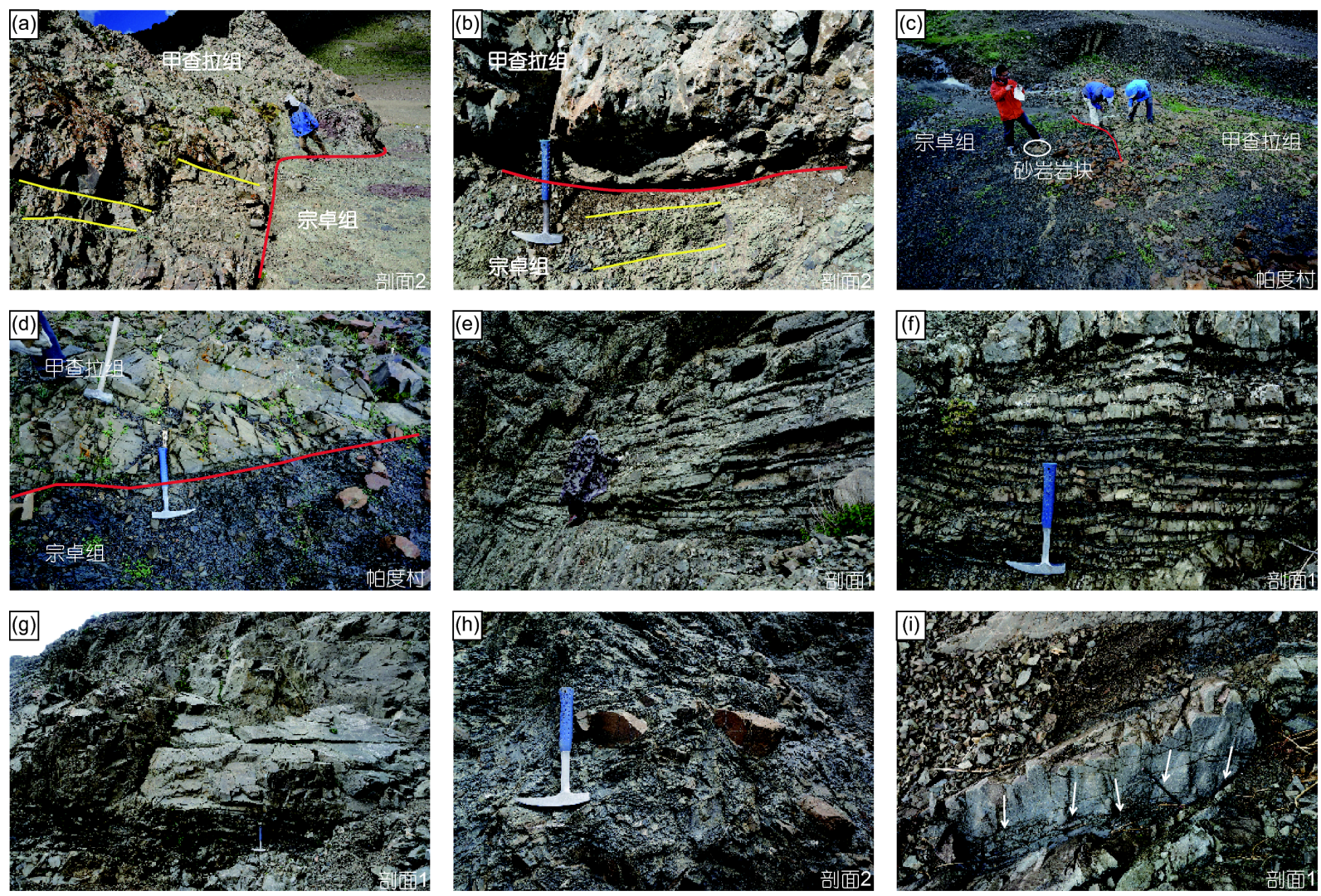

图 4 甲查拉组野外照片

(a)、 (b)显示甲查拉组与宗卓组断层接触, 黄色线条指示岩层, 红色线条指示接触界线; (e)为中细粒砂岩夹灰绿色、灰黑色泥页岩(L1); (f)为薄 层细粒砂岩与灰绿色、灰黑色泥页岩互层(L2); (g)为巨厚层块状砂岩(L3); (h) 为灰黑色页岩夹灰岩、砂岩岩块(L4), 指示滑塌沉积; (i) 为槽模 构造, 指示深水浊流环境, 白色箭头显示古水流方向. 比例尺: 人高约 $1.7 \mathrm{~m}$, 地质锤长约 $40 \mathrm{~cm}$, 铅笔长约 $12 \mathrm{~cm}$, 图片位置参见图 $2 、 3$

\subsection{2 碎屑锆石U-Pb年龄和Hf同位素}

甲查拉组7件样品 (甲查拉山 4 件, 帕度村 3 件)的碎 屑锆石 $\mathrm{U}-\mathrm{Pb}$ 年龄分布类似，集中在80 250、500 800 和1000 1500Ma(图8), 在358 个有效年龄中分别占 $28 \% 、 16 \%$ 和 $25 \%$; 最年轻年龄为 $(73 \pm 1) 、(78 \pm 3)$ 和 $(83$ $\pm 1) \mathrm{Ma}$ ，不协和度分别为 $-2.7 \% 、 3.8 \%$ 和 $-4.8 \%$. 甲查 拉山 4 件样品和帕度村 3 件样品的 $\mathrm{YC} 1 \sigma(2+)$ 年龄分别 为(83.8 \pm 1.3$)$ 和( $86.0 \pm 2.8) \mathrm{Ma}$, 与 $\mathrm{Wu}$ 等(2014)的结果一 致(表3). 帕度村 3 件样品的 36 个 Hff同位素数据显示甲 查拉组中生代锆石的 $\varepsilon_{\mathrm{Hf}}(t)$ 值变化范围较大 $(-15.3 \sim$ 13.8 ), 与甲查拉山中生代锆石的 $\varepsilon_{\mathrm{Hf}}(t)$ 值分布类似(图9) (Wu等, 2014).

\subsection{3 物源解释}

甲查拉组的碎屑组分、碎屑锆石 U-Pb年龄和 $\mathrm{Hf}$
同位素与日喀则弧前盆地昂仁组上段、帕达那组和修 康混杂岩中的一组砂岩岩块高度相似(Wu等, 2010; An 等, 2014, 2017) (图9 11). 碎屑组分中大量的石英和火 山岩岩屑，少量的沉积岩岩屑和变质岩岩屑(图6、7) 与冈底斯弧和中拉萨地体的岩石组合吻合(潘桂棠等, 2006; Kapp等, 2005; Zhu等, 2011). 最年轻的碎屑锆石 年龄为 $84 \mathrm{Ma}$ (表3), 同期的火山活动仅在北侧的冈底 斯弧出露, 中生代锆石的 $\varepsilon_{\mathrm{Hf}}(t)$ 值分布与冈底斯弧和中 拉萨地体吻合(图9)(Kapp等, 2005; Chu等, 2006; 李皓 扬等, 2007; 张宏飞等, 2007a、b; Ji等, 2009; Zhu等, 2009，2011). 这些证据指示甲查拉组的物源来自亚洲 大陆的冈底斯弧和中拉萨地体, 与绝大部分前人的结 论一致(魏玉帅等, 2006; 蔡福龙等, 2008; Wu等2014). 蔡福龙等(2013)认为甲查拉组的物源再旋回自日喀则 弧前盆地、增生楔和朗杰学群. 但甲查拉组的砂岩岩 屑以火山岩岩屑为主而不是沉积岩岩屑, 与之矛盾. 

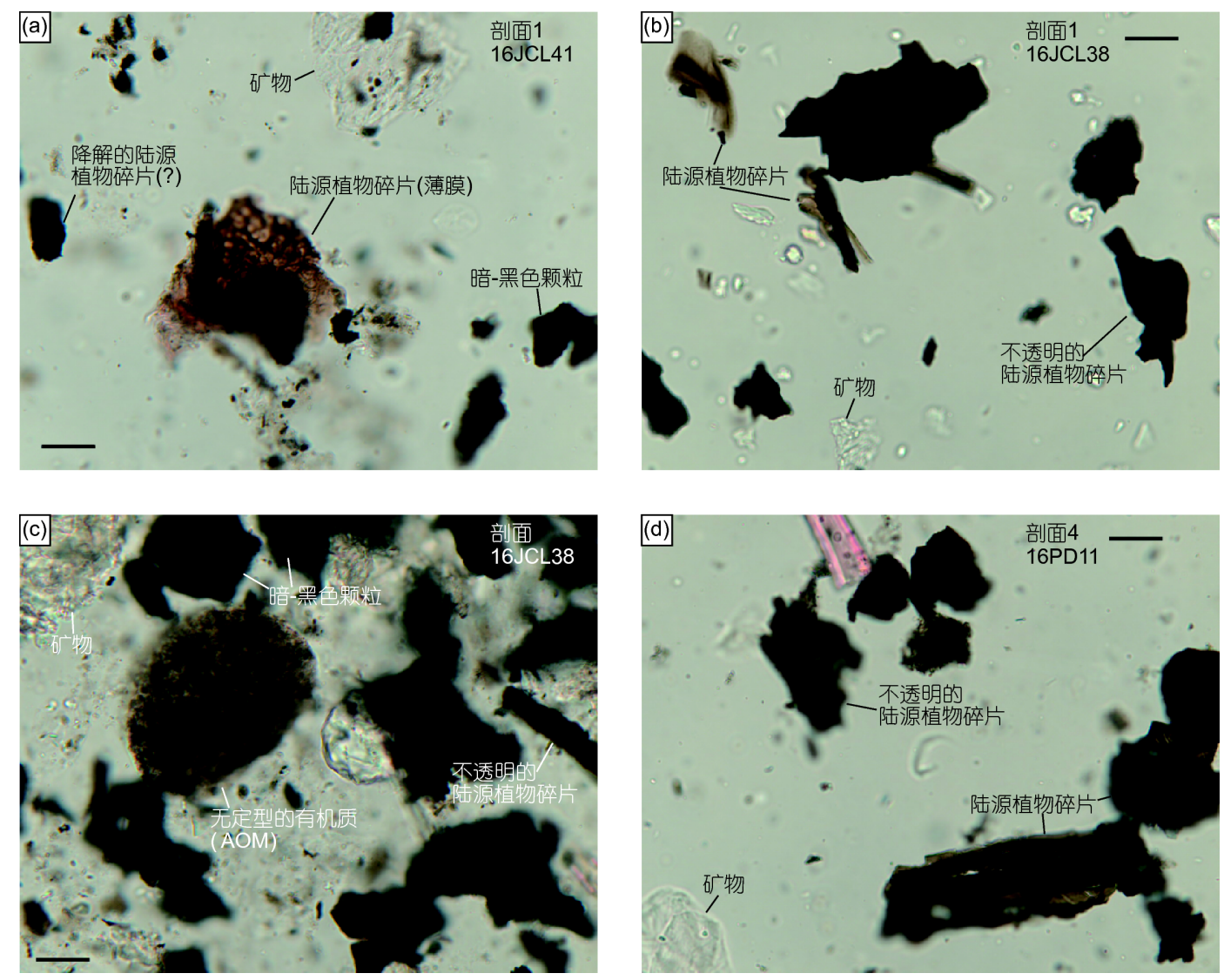

图 5 甲查拉组孢粉、沟鞭藻化石分析处理结果

显示缺乏保存良好的孢粉、沟鞭藻化石, 含大量暗-黑色的陆源植物碎片和矿物颗粒. 黑色比例尺为 $20 \mu \mathrm{m}$

表 2 甲查拉组砂岩碎屑组分a)

\begin{tabular}{ccccccccc}
\hline 样品 & 岩性 & Qm & Qp & F & Lv & Ls & Lm & 合计 \\
\hline 14QM111 & 长石质岩屑石英砂岩 & 234 & 10 & 62 & 72 & 18 & 7 & 403 \\
14QM113 & 长石质岩屑石英砂岩 & 238 & 9 & 70 & 67 & 10 & 8 & 402 \\
14QM115 & 长石质岩屑石英砂岩 & 229 & 8 & 72 & 57 & 29 & 10 & 405 \\
14QM116 & 岩屑质石英砂岩 & 299 & 2 & 31 & 54 & 10 & 14 & 410 \\
14QM119 & 长石质岩屑石英砂岩 & 246 & 8 & 60 & 68 & 14 & 9 & 405 \\
08JCL03 & 岩屑质长石石英砂岩 & 206 & 3 & 121 & 73 & 3 & 410 & 4 \\
08JCL04 & 岩屑质长石石英砂岩 & 199 & 4 & 114 & 85 & 1 & 2 \\
08JCL07 & 长石质岩屑石英砂岩 & 189 & 1 & 101 & 110 & 0 & 1 & 405 \\
08JCL13 & 岩屑质长石石英砂岩 & 192 & 4 & 134 & 68 & 4 & 0 & 402 \\
08JCL15 & 岩屑质长石石英砂岩 & 159 & 5 & 140 & 91 & 2 & 3 & 400 \\
\hline
\end{tabular}

a) $\mathrm{Qm}$-单晶石英, $\mathrm{Qp}$-多晶石英, $\mathrm{F}$-长石, $\mathrm{Lv}$-火山岩岩屑, $\mathrm{Ls}^{-}$沉积岩岩屑, $\mathrm{Lm}$-变质岩岩屑. 表中的单位为颗数

\section{5 讨论}

\section{1 甲查拉组的时代}

李国彪等(2004)根据孢粉、沟鞭藻化石将甲查拉
组的时代限定为古新世-早始新世, 然而反复对照核查 其提供的㘧粉、沟鞭藻化石图版后发现: (1) 仅部分化 石图版与其给出的名称相符 (如沟鞭澡化石22 24), 难 以确认古新世/始新世的沟鞭藻化石Apectodinium, 

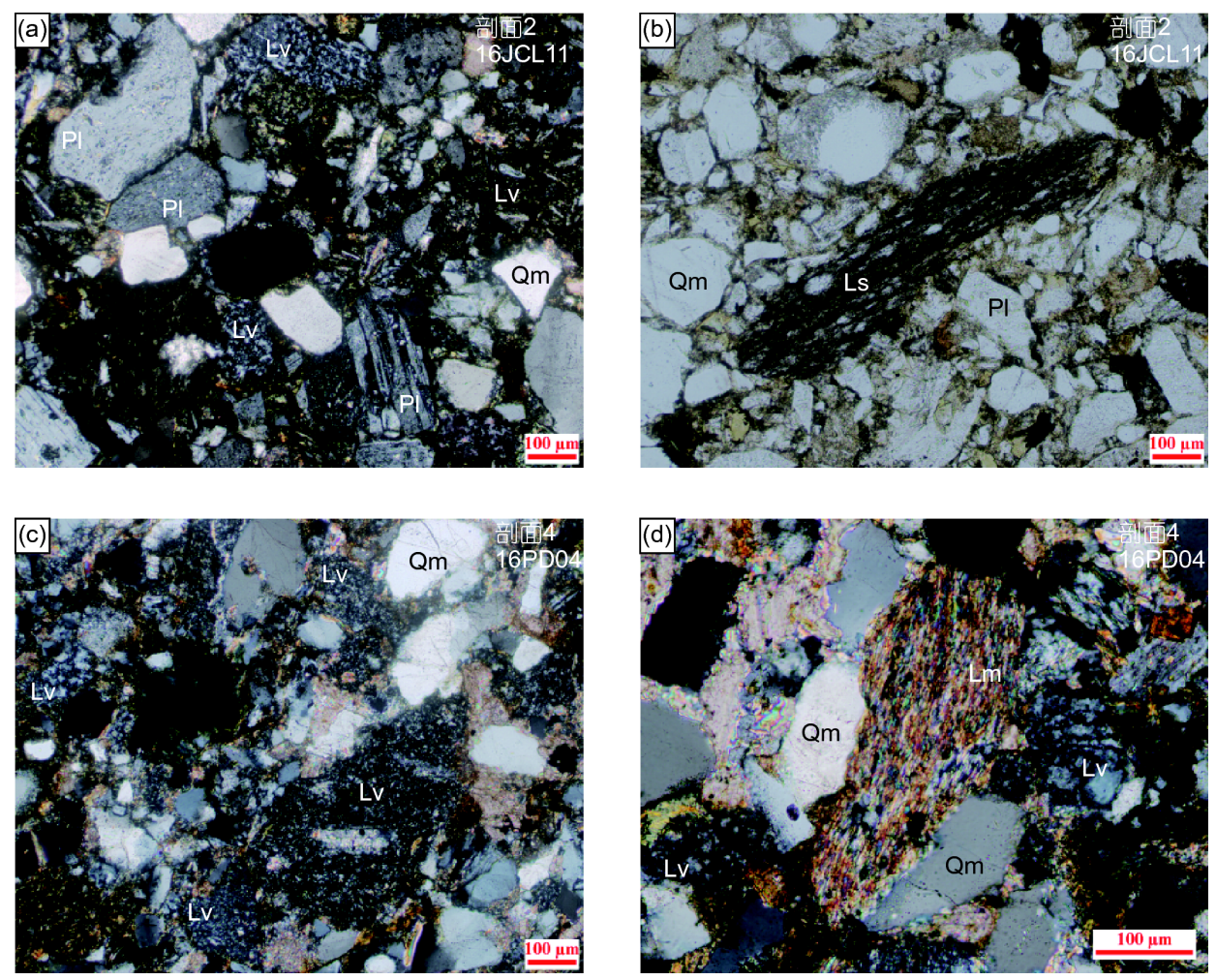

图 6 甲查拉组砂岩显微照片

显示岩屑以中酸性火山岩岩屑为主, 可见少量沉积岩岩屑和变质岩岩屑; 矿物、岩屑缩写参见表2
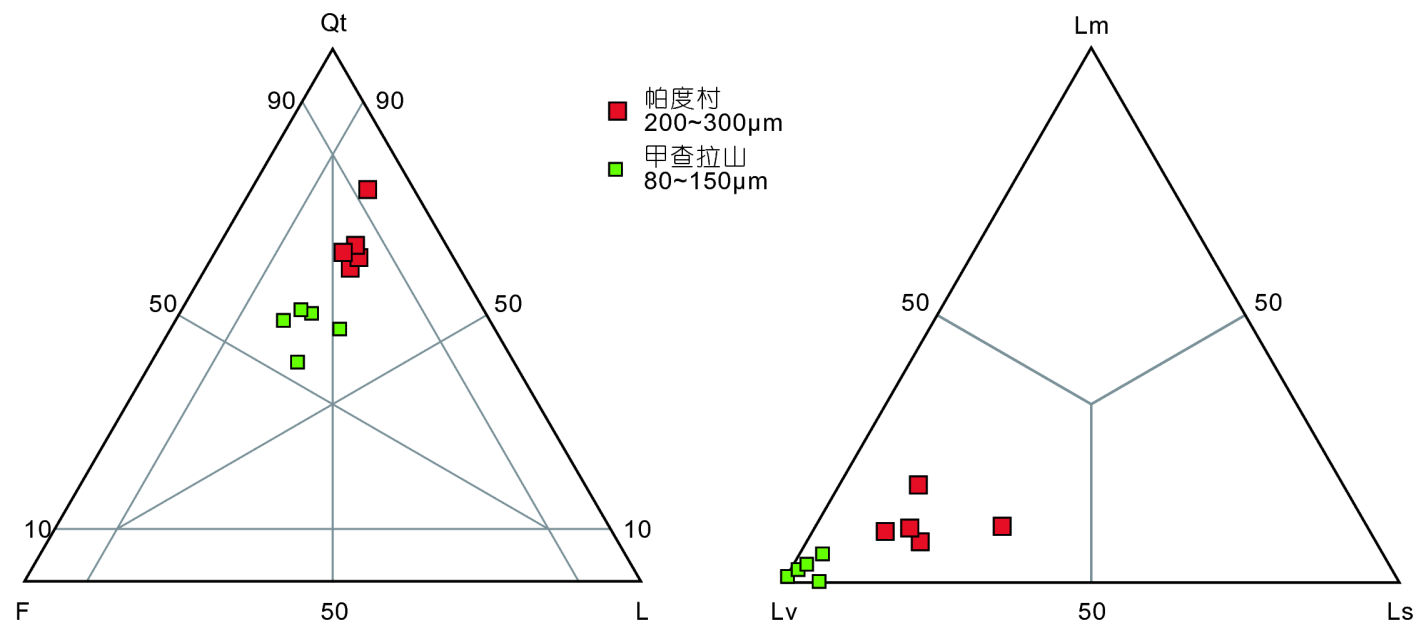

图 7 甲查拉组碎屑组分三角图

$\mathrm{Qt}$-总石英; $\mathrm{Qt}=\mathrm{Qm}+\mathrm{Qp} ; \mathrm{F}-$ 长石; $\mathrm{L}$-岩屑, $\mathrm{L}=\mathrm{Lv}+\mathrm{Ls}+\mathrm{Lm}$. 矿物、岩屑缩写参见表2

Samlandia和Kisselovia是否存在；(2) 其化石分布图提 及的一些关键种属(如Homotryblium, Deflandrea和 Rhombodinium)没有提供图版. 因此，仅根据李国彪等 (2004)提供的狍粉、沟鞭藻化石图版不足以确认甲查
拉组的时代为古新世-早始新世.

考虑到物源区冈底斯弧岩浆活动在白严纪-古近 纪一直持续, 我们认为甲查拉组的时代很可能是最年 轻碎屑锆石指示的晚白严世 $(88 \sim 84 \mathrm{Ma})$, 主要证据 

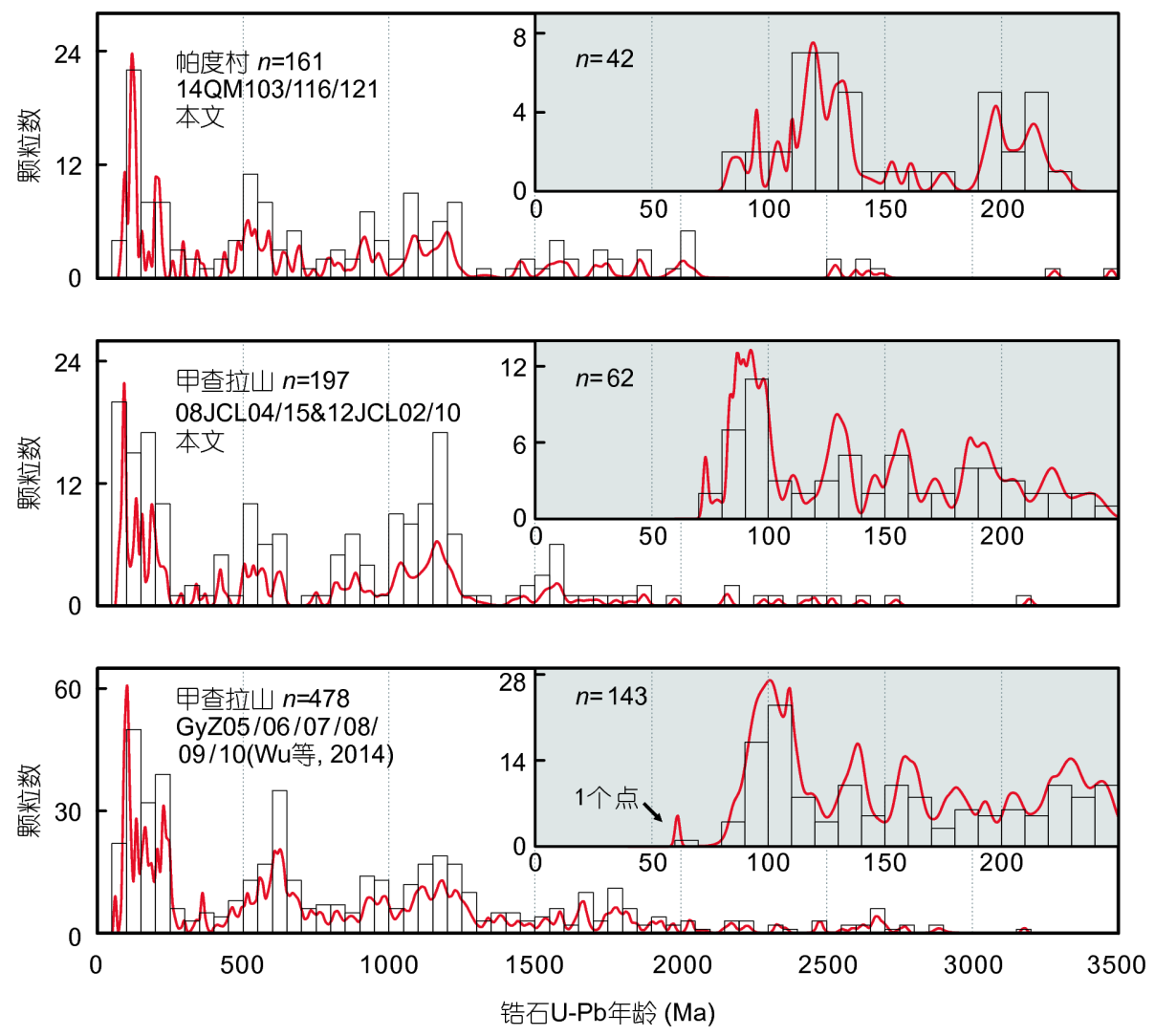

图 8 甲查拉组碎屑锆石U-Pb年龄概率密度图

如下.

(1) 邻区存在与甲查拉组相似的晚白严世地层和 岩块，如拉孜地区修康混杂岩中的一组砂岩岩块(An 等，2017)，日喀则弧前盆地的昂仁组上段和帕达那组 (Wan等, 1998; Wu等, 2010; An等, 2014). 这些地层和 岩块的物源均来自冈底斯弧和中拉萨地体，碎屑组 分、碎屑锆石 $\mathrm{U}-\mathrm{Pb}$ 年龄和 $\mathrm{Hf}$ 同位素与甲查拉组高度 相似(图1、9 11).

(2) 邻区不存在与甲查拉组相似的古新世-早始新 世地层. 无论是雅鲁藏布缝合带内深水的桑单林组和 者雅组(Wang等, 2011; DeCelles等, 2014), 还是北侧日 喀则弧前盆地顶部浅水的曲下组和加拉孜组 $(\mathrm{Hu}$ 等, 2016a)，还是南侧特提斯喜马拉雅顶部的恩巴组和扎 果组(Najman等, 2010; Hu等, 2012, Li 等, 2015) (图1), 它们的碎屑锆石年龄都与甲查拉组存在显著差异. 甲 查拉组最年轻的碎屑锆石年龄峰为 $86 \mathrm{Ma}$, 中生代以前 的锆石含量较高 $(71 \%)$; 而上述这些地层最年轻的碎屑 锆石年龄峰为54 59Ma，中生代以前的锆石含量较低
(15 40\%)(表3, 图10、11).

Dickinson和Gehrels(2009)的研究表明，当物源区 存在持续的岩浆活动时，碎屑锆石的 $\mathrm{YC} 1 \sigma(2+)$ 年龄可 以有效地约束地层的沉积年龄. 甲查拉组符合这一条 件, 甲查拉山 4 件样品的 $\mathrm{YC} 1 \sigma(2+)$ 年龄为 $(83.8 \pm 1.3) \mathrm{Ma}$; 帕度村 3 件样品的 $\mathrm{YC} 1 \sigma(2+)$ 年龄为 $(86.0 \pm 2.8) \mathrm{Ma} ; \mathrm{Wu}$ 等 $(2014)$ 甲查拉山 6 件样品的 $\mathrm{YC} 1 \sigma(2+)$ 年龄为 $(88.2$ $\pm 2.4) \mathrm{Ma}$ (表3). 因此, 本文认为甲查拉组的时代很可能 为晚白严世(88 84Ma).

\section{2 甲查拉组的大地构造性质}

如果甲查拉组的时代是晚白严世(88 84Ma), 那么 其形成于新特提斯洋向北俯冲至亚洲大陆南缘阶段. 基于甲查拉组的基底、大地构造位置、物源和沉积特 征, 其沉积盆地类型存在三种可能: 弧前盆地、海沟斜 坡盆地和海沟盆地.

虽然日喀则弧前盆地发育与甲查拉组时代、物源 和沉积环境类似的昂仁组上段(Wan等，1998; Wu等, 

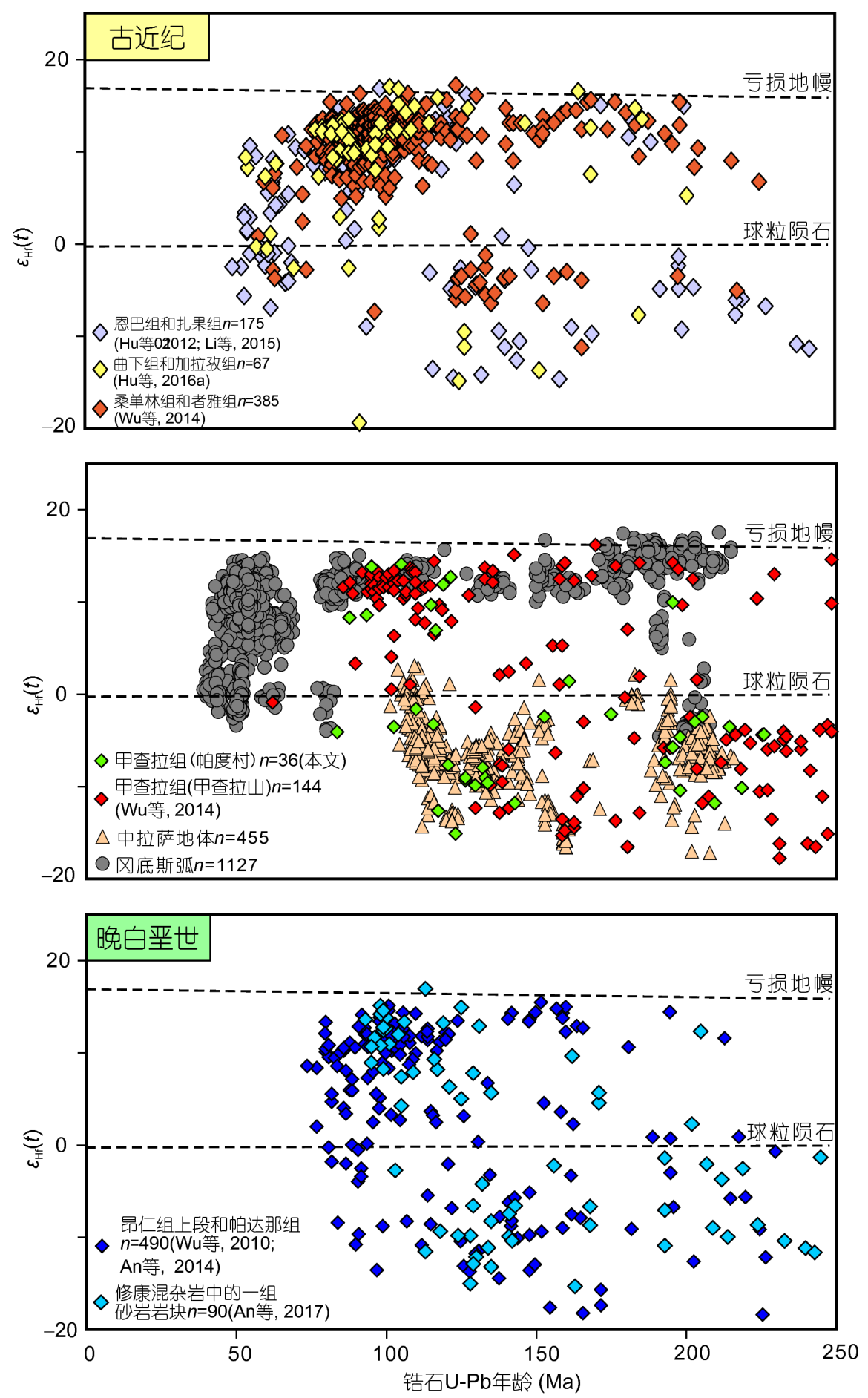

图 9 碎屑锆石 U-Pb年龄- $\varepsilon_{\mathrm{Hr}}(t)$ 图解

显示甲查拉组中生代锆石的 $\varepsilon_{\mathrm{Hf}}(t)$ 分布与冈底斯弧(Chu等, 2006; 李皓扬等, 2007; 张宏飞等, 2007b; Ji等, 2009; Zhu等, 2009, 2011)和中拉萨地体 (Chu等, 2006; 张宏飞等, 2007a; Zhu等, 2011)吻合, 与晚白严世的地层和岩块相似, 与古近纪地层相比其负值所占比例更高

2010; An等, 2014). 但两者的大地构造位置和物质组成 存在明显差异. 甲查拉组出露于蛇绿岩套南侧, 而日喀
则弧前盆地(昂仁组上段)出露于蛇绿岩套北侧(图1). 甲查拉组的石英和中生代以前的锆石含量明显高于昂 

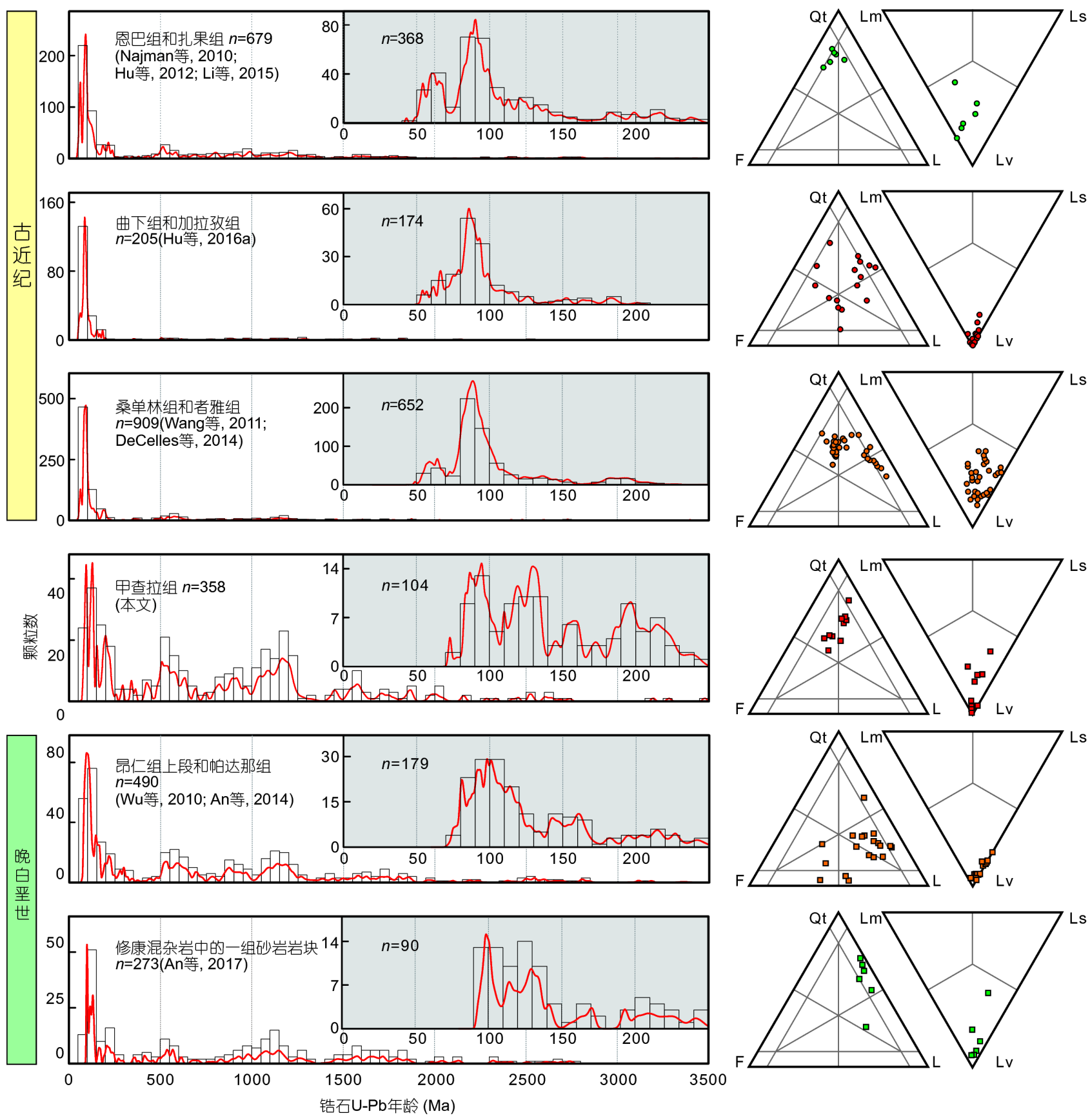

图 10 甲查拉组与邻区晚白严世-古近纪地层和岩块的碎屑锆石U-Pb年龄、碎屑组分对比图

显示甲查拉组与晚白严世地层和岩块相似; 与古近纪地层相比, 甲查拉组缺乏 $84 \sim 50 \mathrm{Ma}$ 的锆石年龄, 且其中生代以前的锆石含量更高

仁组上段(图10、11)，原因可能是两者的古水系不同， 导致中拉萨地体提供的碎屑物质占比不同. 因此，甲 查拉组与昂仁组上段不是同套地层，甲查拉组不是弧 前盆地沉积.

海沟斜坡盆地的发育需要一个大型的增生楔基底
(Underwood和Moore, 1995). 但由于研究区晚白严世亚 洲大陆边缘属于侵蚀型的大陆边缘，不发育大型的增 生楔(图2)(An等, 2017). 因此, 甲查拉组也不是海沟斜 坡盆地沉积.

本文认为甲查拉组属于海沟沉积，证据如下：(1) 
表 3 甲查拉组与邻区白严纪-古近纪地层和岩块的碎屑锆石 $\mathbf{U}-\mathbf{P b}$ 年龄特征 ${ }^{\mathrm{a})}$

\begin{tabular}{|c|c|c|c|c|c|c|}
\hline 地层 & 锆石数 & $\begin{array}{l}\text { YDZ } \\
(\mathrm{Ma})\end{array}$ & $\begin{array}{l}\text { YSG } \\
\text { (Ma) }\end{array}$ & $\begin{array}{l}\text { YPP } \\
\text { (Ma) }\end{array}$ & $\begin{array}{c}\mathrm{YC} 1 \sigma(2+) \\
(\mathrm{Ma})\end{array}$ & $\begin{array}{c}\mathrm{YC} 2 \sigma(3+) \\
(\mathrm{Ma})\end{array}$ \\
\hline 甲查拉组(甲查拉山, 本文) & 197 & $73.2+2 /-2.6$ & $73 \pm 1$ & 86 & $\begin{array}{c}83.8 \pm 1.3 \\
(n=3)\end{array}$ & $\begin{array}{c}84.2 \pm 2.4 \\
(n=5)\end{array}$ \\
\hline 甲查拉组(帕度村,本文) & 161 & $83.7+4.3 /-4.1$ & $84 \pm 2$ & 95 & $\begin{array}{c}86.0 \pm 2.8 \\
(n=2)\end{array}$ & $\begin{array}{c}109.8 \pm 5 \\
(n=4)\end{array}$ \\
\hline 甲查拉组(甲查拉山, Wu等, 2014) & 478 & $60.6+2.6 /-2$ & $61 \pm 1$ & 101 & $\begin{array}{c}88.2 \pm 2.4 \\
(n=6)\end{array}$ & $\begin{array}{c}88.2 \pm 3.1 \\
(n=6)\end{array}$ \\
\hline 恩巴组和扎果组(Hu等, 2012; Li等, 2015) & 679 & $43.2+1.7 /-1.9$ & $43.1 \pm 0.8$ & 54 & $\begin{array}{c}53.0 \pm 0.8 \\
(n=9)\end{array}$ & $\begin{array}{c}51.9 \pm 1.3 \\
(n=8)\end{array}$ \\
\hline 曲下组和加拉孜组(Hu等, 2016a) & 205 & $53.2+1.7 /-3.6$ & $54 \pm 0.9$ & 54 & $\begin{array}{l}55.3 \pm 0.9 \\
(n=5)\end{array}$ & $\begin{array}{c}56.2 \pm 0.8 \\
(n=7)\end{array}$ \\
\hline $\begin{array}{c}\text { 桑单林组和者雅组(Wang等, 2011; DeCelles等, } \\
\text { 2014) }\end{array}$ & 909 & $49.2+1.4 /-2.6$ & $49.1 \pm 0.7$ & 59 & $\begin{array}{l}54.1 \pm 1.0 \\
(n=7)\end{array}$ & $\begin{array}{c}55.8 \pm 0.6 \\
(n=15)\end{array}$ \\
\hline 昂仁组上段和帕达那组(Wu等, 2010; An等, 2014) & 490 & $73.1+3.1 /-4$ & $74 \pm 2$ & 81 & $\begin{array}{l}76.2 \pm 1.6 \\
(n=4)\end{array}$ & $\begin{array}{c}78.5 \pm 1.0 \\
(n=8)\end{array}$ \\
\hline 修康混杂岩中的一组砂岩岩块(An等, 2017) & 273 & $92.7+1.9 /-2.6$ & $93 \pm 1$ & 99 & $\begin{array}{c}94.3 \pm 1.3 \\
\quad(n=4)\end{array}$ & $\begin{array}{c}94.5 \pm 1.2 \\
(n=5)\end{array}$ \\
\hline
\end{tabular}

a) YDZ, 根据"最年轻碎屑锆石"算法计算得到的年龄(Isoplot, Ludwig, 2011); YSG, 最年轻的单个碎屑锆石年龄 $(1 \sigma$ 误差); YPP, 年龄谱图 上的最年轻峰值; $\mathrm{YC} 1 \sigma(2+), 1 \sigma$ 内相互重叠的 $2 ~ 13$ 个最年轻年龄的加权平均值; $\mathrm{YC} 2 \sigma(3+), 2 \sigma$ 内相互重叠的 $3-24$ 个最年轻年龄的加权平均值 (Dickinson和Gehrels, 2009)

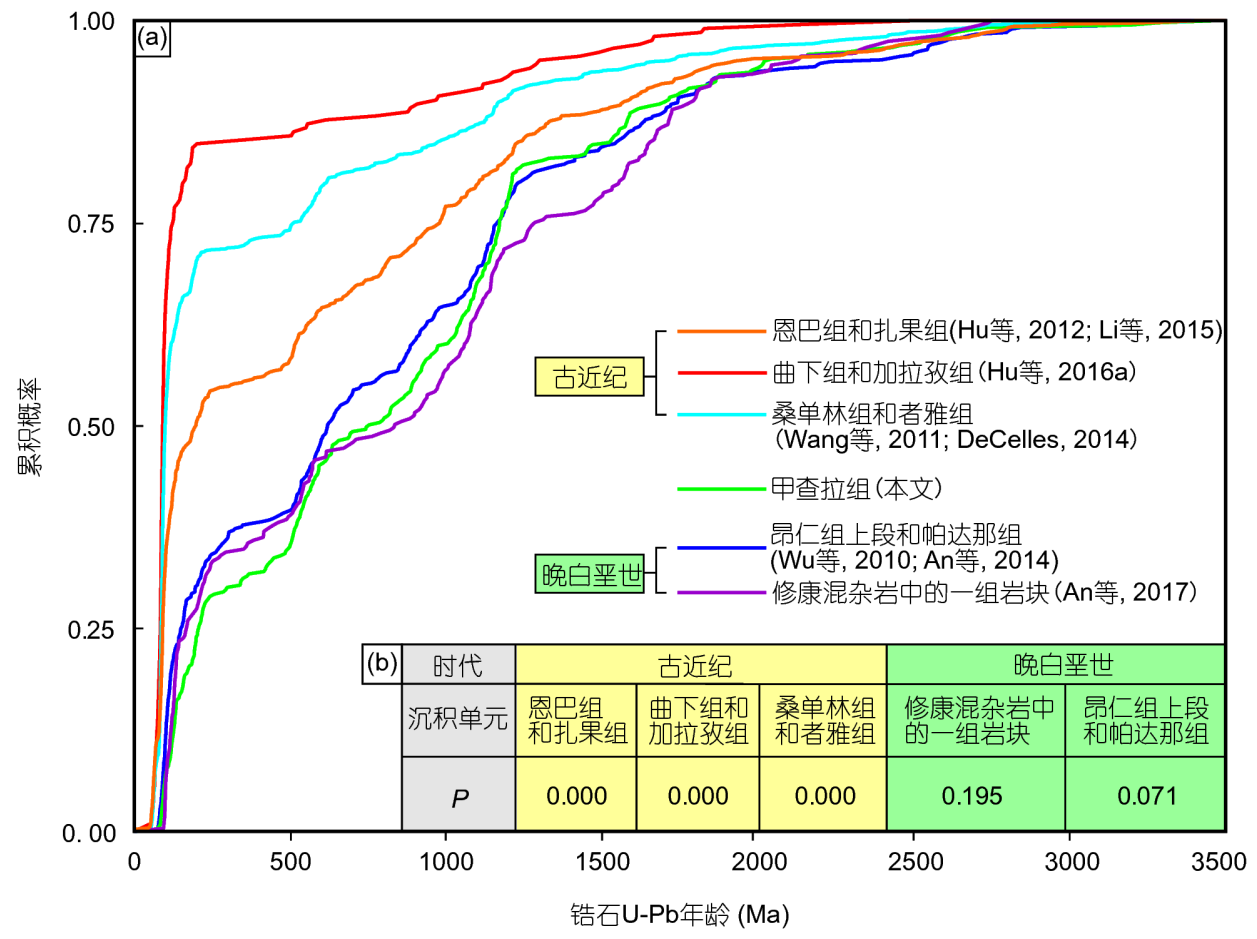

图 11 甲查拉组与邻区晚白严世-古近纪地层和岩块的碎屑锆石U-Pb年龄对比图

(a) 概率累积曲线; (b) K-S检验. $P$ 值随相似性的增加而增加 


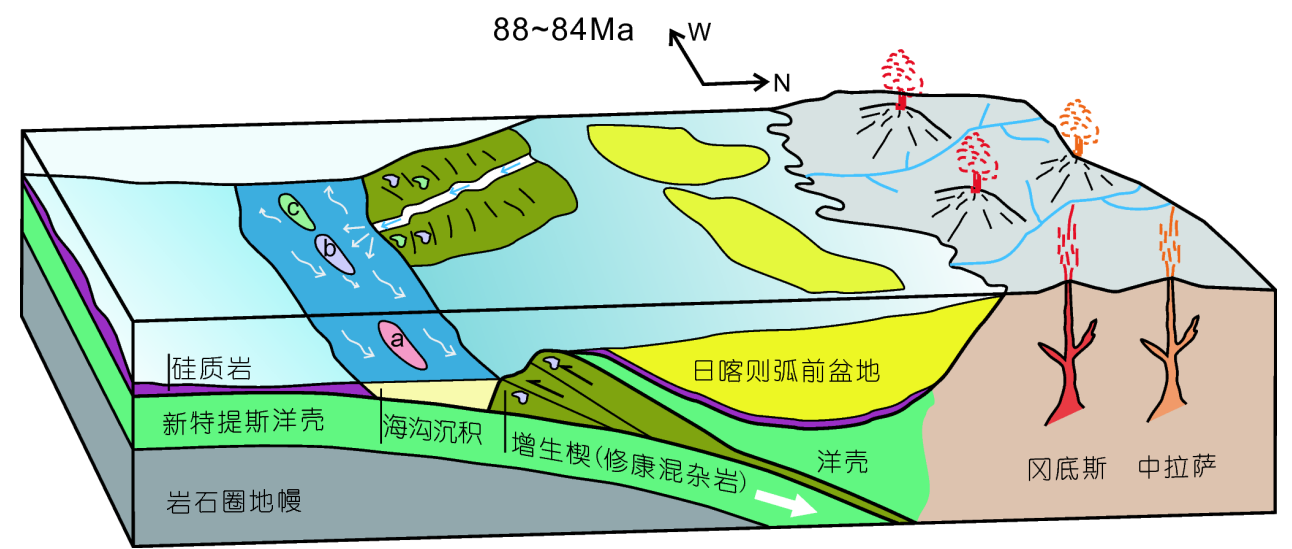

图 12 甲查拉组古地理图

冈底斯弧和中拉萨地体的物质越过日喀则弧前盆地一直到达海沟, 沿轴向通道侧向搬运, 沉积形成甲查拉组(a), 西侧发育同时代的海沟沉积: 修康混杂岩中的一组砂岩岩块(b)和罗岗错组(c)
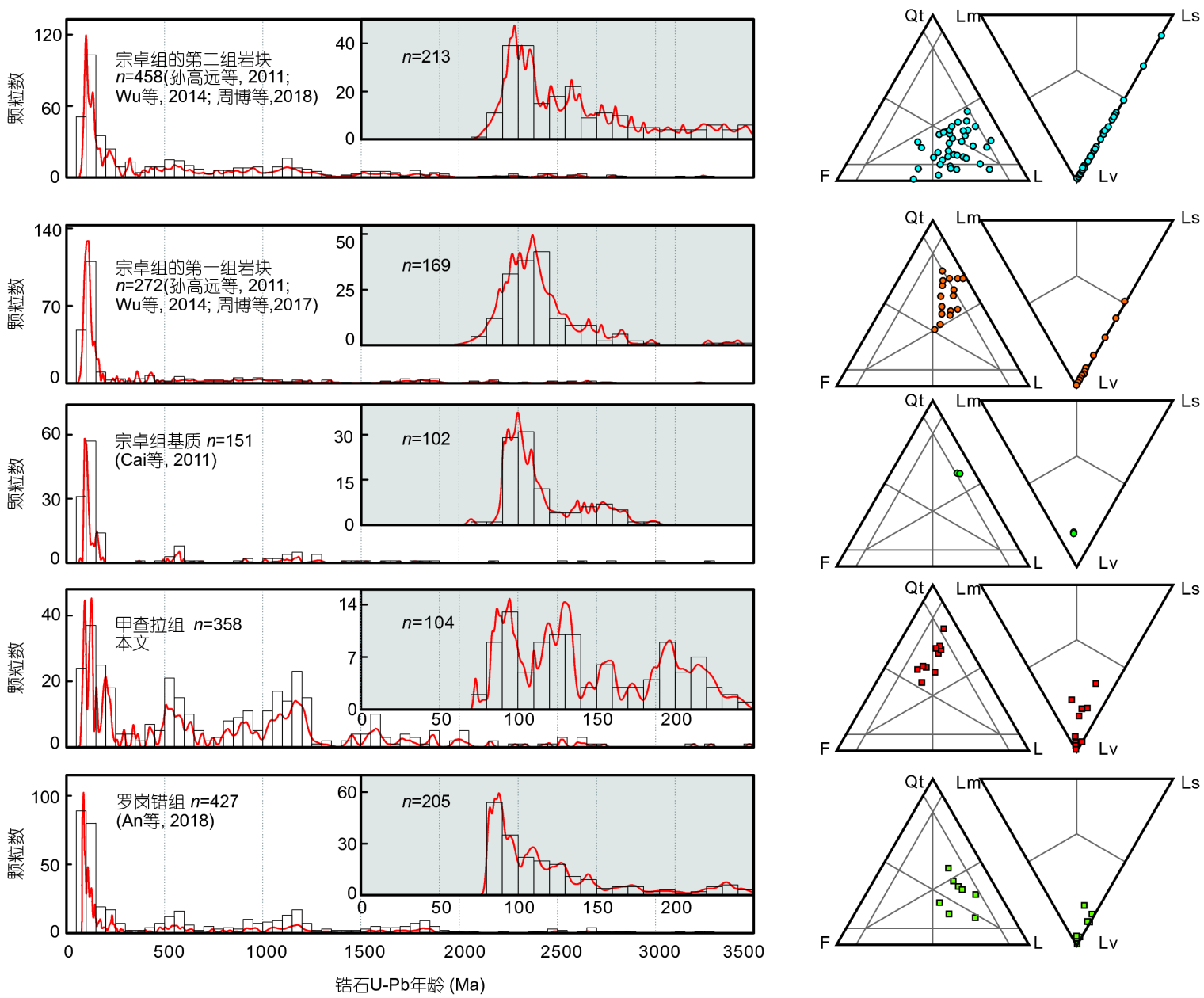

图 13 甲查拉组与宗卓组和罗岗错组的碎屑锆石 $U-P b$ 年龄、碎屑组分对比图

甲查拉组中生代以前的锆石含量明显高于宗卓组和罗岗错组. 甲查拉组的碎屑组分与宗卓组第一组岩块和基质相似, 石英含量明显高于宗卓 组第二组岩块和罗岗错组. 宗卓组数据来自江孜-浪卡子地区, 岩块分组据周博等(2018) 
甲查拉组的构造基底为印度大陆的特提斯喜马拉雅深 水沉积(宗卓组、维美组等), 沉积环境为海底扇; 物源 来自亚洲大陆的冈底斯弧和中拉萨地体，这些特征与 海沟沉积吻合; (2) 修康混杂岩中存在一组母体为晚 白严世海沟沉积的砂岩岩块, 其碎屑组分、碎屑锆石 $\mathrm{U}-\mathrm{Pb}$ 年龄和 $\mathrm{Hf}$ 同位素均与甲查拉组高度相似(图1、 9 11)(An等, 2017).

\section{3 甲查拉组的地质演化}

在晚白严世新特提斯洋俯冲阶段(88 84Ma), 日喀 则弧前盆地发育昂仁组上段, 沉积充填即将结束( An 等, 2014), 此时的俯冲增生楔规模也不大 (An 等, 2017). 因此，冈底斯弧和中拉萨地体的物质可以越过 日喀则弧前盆地和大洋俯冲增生楔到达海沟. 这些物 质到达海沟后沿轴向通道侧向搬运，沉积形成甲查拉 组(图12).

印度-亚洲大陆初始碰撞后(古新世中期), 海沟位 置发育宗卓组(Liu和Aitchison, 2002; 孙高远等, 2011; Cai等, 2011; Wu等, 2014; 周博等, 2018). 在随后的早 期造山阶段, 甲查拉组被推覆至宗卓组之上(图 $4 \mathrm{a} \sim \mathrm{d})$. 碎屑组分、碎屑锆石 $\mathrm{U}-\mathrm{Pb}$ 年龄对比显示尽管两者都 是海沟沉积, 但时代和地质背景差异显著(图13).

目前在甲查拉组西侧也发现了同时代的海沟沉 积, 如拉孜地区修康混杂岩中的一组砂岩岩块(94Ma) (An等, 2017), 萨嘎地区的罗岗错组(88 81Ma)(An等, 2018), 前者作为岩块混杂于增生楔(修康混杂岩), 后者 与增生楔呈断层接触. 碎屑组分、碎屑锆石 $\mathrm{U}-\mathrm{Pb}$ 年龄 对比发现, 罗岗错组砂岩的石英与中生代以前的锆石 含量明显低于甲查拉组(图13), 可能是因为两者的古 水系不同.

\section{6 结论}

地层学与沉积学的研究工作表明甲查拉组的沉积 环境为海底扇, 与宗卓组呈断层接触. 碎屑组分、碎屑 锆石 $\mathrm{U}-\mathrm{Pb}$ 年龄和 $\mathrm{Hf}$ 同位素指示甲查拉组的物源来自 亚洲大陆的冈底斯弧和中拉萨地体. 考虑物源区白严 纪-古近纪持续的岩浆活动, 根据最年轻的碎屑锆石年 龄将地层时代限定为晚白严世(88 84Ma). 综合甲查拉 组的地质特征, 我们认为这套地层属于新特提斯洋俯 冲阶段亚洲南缘的海沟沉积, 由冈底斯弧和中拉萨地
体的物质越过日喀则弧前盆地到达海沟后，沿轴向通 道侧向搬运沉积形成. 印度-亚洲大陆初始碰撞后, 海 沟位置发育宗卓组, 随后的构造运动将甲查拉组推覆 至宗卓组之上.

致谢 感谢王成善院士、吴福元院士、李祥辉教授、万 晓樵教授、李建国教授的有益讨论和建议; 感谢边立曾 教授和Roger Tremain对狍粉、沟鞭藻样品分析处理的帮 助; 感谢周博在野外的帮助; 感谢赖文、薛伟伟在 Hf同位 素测试上的帮助. 感谢审稿人提出的建设性意见.

\section{参考文献}

蔡福龙, 丁林, 张清海, 徐晓霞, 岳雅慧, 张利云, 许强. 2008. 雅鲁藏 布江周缘前陆盆地物源分析及构造演化. 岩石学报, 24: 430-446

蔡福龙, 丁林, 王厚起, 岳雅慧, 来庆洲. 2013. 特提斯喜马拉雅带江 孜地区古近纪地层源区分析. 地质科学, 48: 435-448

丁林, Maksatbek S, 蔡福龙, 王厚起, 宋培平, 纪伟强, 许强, 张利云, Muhammad Q, Upendra B. 2017. 印度与欧亚大陆初始碰撞时 限、封闭方式和过程. 中国科学: 地球科学, 47: 293-309

胡修棉, 王成善, 李祥辉. 2006. 藏南上白严统大洋红层: 岩石类型、 沉积环境与颜色成因. 中国科学 $\mathrm{D}$ 辑: 地球科学, 36: 811-821

胡修棉, 李娟, 安慰, 王建刚. 2017a. 藏南白严纪-古近纪岩石地层厘 定与构造地层划分. 地学前缘, 24: 174-194

胡修棉, 王建刚, 安慰, Garzanti E, 李娟. 2017b. 利用沉积记录精确约 束印度-亚洲大陆碰撞时间与过程. 中国科学: 地球科学, 47: 261283

李国彪, 万晓樵, 刘文灿, 梁定益, Yun H. 2004. 雅鲁藏布江缝合带南 侧古近纪海相地层的发现及其构造意义. 中国科学 D辑: 地球科 学, 34: 228-240

李皓扬, 钟孙霖, 王彦斌, 朱弟成, 杨进辉, 宋彪, 刘敦一, 吴福元. 2007. 藏南林周盆地林子宗火山岩的时代、成因及其地质意义: 锆石U-Pb年龄和Hff同位素证据. 岩石学报, 23:493-500

李祥辉, 王成善, 万晓樵, 陶然. 1999. 藏南江孜县床得剖面侏罗-白严 纪地层层序及地层划分. 地层学杂志, 24: 303-309

李祥辉, 王成善 胡修棉. 2000. 深海相中的砂质碎屑流沉积: 以西藏 特提斯喜马拉雅侏罗-白垔系为例. 矿物岩石, 20: 45-51

萄新望. 1998. 西藏江孜地区上白严统宗卓组沉积混杂堆积基本特 征及构造意义. 岩相古地理, 18: 28-33

潘桂棠, 丁 俊, 姚冬生, 王立全. 2004. 青藏高原及邻区1:150万地质 图说明书. 成都: 成都地图出版社

潘桂棠, 莫宣学, 侯增谦, 朱弟成, 王立全, 李光明, 赵志丹, 耿全如, 廖忠礼. 2006. 冈底斯造山带的时空结构及演化. 岩石学报, 22: $521-533$

孙高远, 胡修棉, 王建刚. 2011. 藏南江孜县白沙地区宗卓混杂岩: 岩 
石组成与物源区分析. 地质学报, 85: 1343-1351

王成善, 李祥辉, 万晓樵, 陶然. 2000. 西藏南部江孜地区白严系的厘 定. 地质学报, 74: 97-107

魏玉帅, 王成善, 李祥辉, 曹珂. 2006. 藏南古近纪甲查拉组物源分析 及其对印度-欧亚大陆碰撞启动时间的约束. 矿物岩石, 26: 46-55

张宏飞, 徐旺春, 郭建秋, 宗克清, 蔡宏明. 2007a. 冈底斯印支期造山 事件: 花岗岩类锆石 U-Pb 年代学和岩石成因证据. 地球科学, 32 : 155-166

张宏飞, 徐旺春, 郭建秋, 宗克清, 蔡宏明, 袁洪林. 2007b. 冈底斯南 缘变形花岗岩锆石 $\mathrm{U}-\mathrm{Pb}$ 年龄和 $\mathrm{Hf}$ 同位素组成:新特提斯洋早侏 罗世俯冲作用的证据. 岩石学报, 23: 1347-1353

周博, 胡修棉, 安慰, 马安林, 赖文. 2018. 印度-亚洲大陆碰撞初期的 海沟沉积：藏东南宗卓组沉积岩石学与物源分析. 地质学报, 92:1-14

朱弟成, 王青, 赵志丹. 2017. 岩浆岩定量限定陆-陆碰撞时间和过程 的方法和实例. 中国科学: 地球科学, 47: 657-673

An W, Hu X, Garzanti E. 2017. Sandstone provenance and tectonic evolution of the Xiukang Mélange from Neotethyan subduction to India-Asia collision (Yarlung-Zangbo suture, south Tibet). Gondwana Res, 41: 222-234

An W, Hu X, Garzanti E, BouDagher-Fadel M K, Wang J, Sun G. 2014 Xigaze forearc basin revisited (South Tibet): Provenance changes and origin of the Xigaze Ophiolite. Geol Soc Am Bull, 126: 15951613

An W, Hu X M, Garzanti E. 2018. Discovery of Upper Cretaceous NeoTethyan trench deposits in south Tibet (Luogangcuo Formation). Lithosphere, https://doi.org/10.1130/L690.1

Andersen T. 2002. Correction of common lead in U-Pb analyses that do not report ${ }^{204} \mathrm{~Pb}$. Chem Geol, 192: 59-79

Beck R A, Burbank D W, Sercombe W J, Riley G W, Barndt J K, Berry J R, Afzal J, Khan A M, Jurgen H, Metje J, Cheema A, Shafique N A, Lawrence R D, Khan M A. 1995. Stratigraphic evidence for an early collision between northwest India and Asia. Nature, 373: 5558

Cai F, Ding L, Yue Y. 2011. Provenance analysis of upper Cretaceous strata in the Tethys Himalaya, southern Tibet: Implications for timing of India-Asia collision. Earth Planet Sci Lett, 305: 195-206

Cai F, Ding L, Leary R J, Wang H, Xu Q, Zhang L, Yue Y. 2012. Tectonostratigraphy and provenance of an accretionary complex within the Yarlung-Zangpo suture zone, southern Tibet: Insights into subduction-accretion processes in the Neo-Tethys. Tectonophysics, 574-575: 181-192

Chen X, Wang C, Kuhnt W, Holbourn A, Huang Y, Ma C. 2011 Lithofacies, microfacies and depositional environments of Upper Cretaceous Oceanic red beds (Chuangde Formation) in southern Tibet. Sediment Geol, 235: 100-110
Chu M F, Chung S L, Song B, Liu D, O'Reilly S Y, Pearson N J, Ji J, Wen D J. 2006. Zircon U-Pb and Hf isotope constraints on the Mesozoic tectonics and crustal evolution of southern Tibet. Geology, 34: 745-748

Dai J, Wang C, Polat A, Santosh M, Li Y, Ge Y. 2013. Rapid forearc spreading between 130 and 120 Ma: Evidence from geochronology and geochemistry of the Xigaze ophiolite, southern Tibet. Lithos, 172-173: $1-16$

DeCelles P G, Kapp P, Gehrels G E, Ding L. 2014. Paleocene-Eocene foreland basin evolution in the Himalaya of southern Tibet and Nepal: Implications for the age of initial India-Asia collision. Tectonics, 33: 824-849

Dickinson W R, Gehrels G E. 2009. Use of U-Pb ages of detrital zircons to infer maximum depositional ages of strata: A test against a Colorado Plateau Mesozoic database. Earth Planet Sci Lett, 288: $115-125$

Einsele G, Liu B, Dürr S, Frisch W, Liu G, Luterbacher H P, Ratschbacher L, Ricken W, Wendt J, Wetzel A, Yu G, Zheng H. 1994. The Xigaze forearc basin: Evolution and facies architecture (Cretaceous, Tibet). Sediment Geol, 90: 1-32

Gansser A. 1980. The significance of the Himalayan suture zone. Tectonophysics, 62: 37-52

Garzanti E. 1999. Stratigraphy and sedimentary history of the Nepal Tethys Himalaya passive margin. J Asian Earth Sci, 17: 805-827

Garzanti E, Hu X M. 2015. Latest Cretaceous Himalayan tectonics: Obduction, collision or Deccan-related uplift? Gondwana Res, 28: $165-178$

Garzanti E. 2016. From static to dynamic provenance analysisSedimentary petrology upgraded. Sediment Geol, 336: 3-13

Göpel C, Allègre C J, Xu R H. 1984. Lead isotopic study of the Xigaze ophiolite (Tibet): The problem of the relationship between magmatites (gabbros, dolerites, lavas) and tectonites (harzburgites). Earth Planet Sci Lett, 69: 301-310

Griffin W L, Pearson N J, Belousova E, Jackson S E, van Achterbergh E, O'Reilly S Y, Shee S R. 2000. The Hf isotope composition of cratonic mantle: LAM-MC-ICPMS analysis of zircon megacrysts in kimberlites. Geochim Cosmochim Acta, 64: 133-147

Guilmette C, Hébert R, Wang C, Villeneuve M. 2009. Geochemistry and geochronology of the metamorphic sole underlying the Xigaze Ophiolite, Yarlung Zangbo Suture Zone, South Tibet. Lithos, 112: 149-162

Guilmette C, Hébert R, Dostal J, Indares A, Ullrich T, Bédard É, Wang C. 2012. Discovery of a dismembered metamorphic sole in the Saga ophiolitic mélange, South Tibet: Assessing an Early Cretaceous disruption of the Neo-Tethyan supra-subduction zone and consequences on basin closing. Gondwana Res, 22: 398-414 
Hébert R, Bezard R, Guilmette C, Dostal J, Wang C S, Liu Z F. 2012. The Indus-Yarlung Zangbo ophiolites from Nanga Parbat to Namche Barwa syntaxes, southern Tibet: First synthesis of petrology, geochemistry, and geochronology with incidences on geodynamic reconstructions of Neo-Tethys. Gondwana Res, 22: 377-397

Hu X, Jansa L, Wang C, Sarti M, Bak K, Wagreich M, Michalik J, Soták J. 2005. Upper Cretaceous oceanic red beds (CORBs) in the Tethys: Occurrences, lithofacies, age, and environments. Cretac Res, 26: $3-20$

Hu X, Jansa L, Chen L, Griffin W L, O'Reilly S Y, Wang J. 2010. Provenance of Lower Cretaceous Wölong Volcaniclastics in the Tibetan Tethyan Himalaya: Implications for the final breakup of Eastern Gondwana. Sediment Geol, 223: 193-205

Hu X, Sinclair H D, Wang J, Jiang H, Wu F. 2012. Late CretaceousPalaeogene stratigraphic and basin evolution in the Zhepure Mountain of southern Tibet: Implications for the timing of IndiaAsia initial collision. Basin Res, 24: 520-543

Hu X, Garzanti E, Moore T, Raffi I. 2015. Direct stratigraphic dating of India-Asia collision onset at the Selandian (middle Paleocene, $59 \pm$ $1 \mathrm{Ma})$. Geology, 43: 859-862

Hu X, Wang J, Boudagher-Fadel M, Garzanti E, An W. 2016a. New insights into the timing of the India-Asia collision from the Paleogene Quxia and Jialazi formations of the Xigaze forearc basin, South Tibet. Gondwana Res, 32: 76-92

Hu X, Garzanti E, Wang J, Huang W, An W, Webb A. 2016b. The timing of India-Asia collision onset-Facts, theories, controversies. Earth-Sci Rev, 160: 264-299

Ingersoll R V, Bullard T F, Ford R L, Grimm J P, Pickle J D, Sares S W. 1984. The effect of grain size on detrital modes: A test of the GazziDickinson point-counting method. J Sediment Res, 54: 103-116

Jackson S E, Pearson N J, Griffin W L, Belousova E A. 2004. The application of laser ablation-inductively coupled plasma-mass spectrometry to in situ U-Pb zircon geochronology. Chem Geol, 211: 47-69

Jadoul F, Berra F, Garzanti E. 1998. The Tethys Himalayan passive margin from late Triassic to early Cretaceous (South Tibet). J Asian Earth Sci, 16: 173-194

Ji W Q, Wu F Y, Chung S L, Li J X, Liu C Z. 2009. Zircon U-Pb geochronology and $\mathrm{Hf}$ isotopic constraints on petrogenesis of the Gangdese batholith, southern Tibet. Chem Geol, 262: 229-245

Kapp P, Yin A, Harrison T M, Ding L. 2005. Cretaceous-Tertiary shortening, basin development, and volcanism in central Tibet. Geol Soc Am Bull, 117: 865-878

Leary R J, DeCelles P G, Quade J, Gehrels G E, Waanders G. 2016. The Liuqu Conglomerate, southern Tibet: Early Miocene basin development related to deformation within the Great Counter Thrust system. Lithosphere, 8: 427-450

Lee H Y, Chung S L, Lo C H, Ji J, Lee T Y, Qian Q, Zhang Q. 2009. Eocene Neotethyan slab breakoff in southern Tibet inferred from the Linzizong volcanic record. Tectonophysics, 477: 20-35

Li J, Peng J, Batten D J. 2013. Palynostratigraphy of a JurassicCretaceous transitional succession in the Himalayan Tethys, southern Xizang (Tibet), China. Cretac Res, 46: 123-135

Li G, Kohn B, Sandiford M, Xu Z, Wei L. 2015. Constraining the age of Liuqu Conglomerate, southern Tibet: Implications for evolution of the India-Asia collision zone. Earth Planet Sci Lett, 426: 259-266

Li J, Hu X, Garzanti E, An W, Wang J. 2015. Paleogene carbonate microfacies and sandstone provenance (Gamba area, South Tibet): Stratigraphic response to initial India-Asia continental collision. J Asian Earth Sci, 104: 39-54

Li X, Wang C, Hu X. 2005. Stratigraphy of deep-water Cretaceous deposits in Gyangze, southern Tibet, China. Cretac Res, 26: 33-41

Liu J, Aitchison J C. 2002. Upper paleocene radiolarians from the Yamdrok mélange, south Xizang (Tibet), China. Micropaleontol, 145-154

Ludwig, K.R., 2011, Isoplot/Ex Version 4: A Geochronological Toolkit for Microsoft Excel. Berkeley Geochronology Center Special Publication 4. 70

Mo X, Niu Y, Dong G, Zhao Z, Hou Z, Zhou S, Ke S. 2008. Contribution of syncollisional felsic magmatism to continental crust growth: A case study of the Paleogene Linzizong volcanic Succession in southern Tibet. Chem Geol, 250: 49-67

Mutti E, Ricci Lucchi F. 1978. Turbidites of the northern Apennines: introduction to facies analysis. Int Geol Rev, 20: 125-166

Najman Y, Appel E, Boudagher-Fadel M, Bown P, Carter A, Garzanti E, Godin L, Han J, Liebke U, Oliver G, Parrish R, Vezzoli G. 2010. Timing of India-Asia collision: Geological, biostratigraphic, and palaeomagnetic constraints. J Geophys Res, 115: 1-70

Orme D A, Carrapa B, Kapp P. 2015. Sedimentology, provenance and geochronology of the upper Cretaceous-lower Eocene western Xigaze forearc basin, southern Tibet. Basin Res, 27: 387-411

Ratschbacher L, Frisch W, Liu G, Chen C. 1994. Distributed deformation in southern and western Tibet during and after the India-Asia collision. J Geophys Res, 99: 19917-19945

Schärer U, Xu R H, Allègre C J. 1984. U-Pb geochronology of Gangdese (Transhimalaya) plutonism in the Lhasa-Xigaze region, Tibet. Earth Planet Sci Lett, 69: 311-320

Söderlund U, Patchett P J, Vervoort J D, Isachsen C E. 2004. The ${ }^{176} \mathrm{Lu}$ decay constant determined by $\mathrm{Lu}-\mathrm{Hf}$ and $\mathrm{U}-\mathrm{Pb}$ isotope systematics of Precambrian mafic intrusions. Earth Planet Sci Lett, 219: 311324

Thornburg T M, Kulm L D. 1987. Sedimentation in the Chile Trench: 
Depositional morphologies, lithofacies, and stratigraphy. Geol Soc Am Bull, 98: 33-52

Underwood M B, Moore G. 1995. Trenches and trench-slope basins. In: Tectonics of Sedimentary Basins. New Jersey: Blackwell Science. 179-219

van Achterbergh E, Ryan C, Jackson S, Griffin W. 2001. Data reduction software for LA-ICPMS, Laser-Ablation-ICPMS in the Earth Sciences: Principles and Applications. Mineral Ass Canada Short Course, 29: 239-243

Wan X Q, Wang L, Wang C X, Jansa L. 1998. Discovery and significance of Cretaceous fossils from the Xigaze Forearc Basin, Tibet. J Asian Earth Sci, 16: 217-223

Wang C, Hu X, Sarti M, Scott R W, Li X. 2005. Upper Cretaceous oceanic red beds in southern Tibet: A major change from anoxic to oxic, deep-sea environments. Cretac Res, 26: 21-32

Wang C, Li X, Liu Z, Li Y, Jansa L, Dai J, Wei Y. 2012. Revision of the Cretaceous-Paleogene stratigraphic framework, facies architecture and provenance of the Xigaze forearc basin along the Yarlung Zangbo suture zone. Gondwana Res, 22: 415-433

Wang J, Hu X, Jansa L, Huang Z. 2011. Provenance of the Upper Cretaceous-Eocene deep-water sandstones in Sangdanlin, Southern Tibet: Constraints on the Timing of Initial India-Asia Collision. J Geol, 119: 293-309

Wang J G, Hu X M, Garzanti E, Wu F Y. 2013. Upper OligoceneLower Miocene Gangrinboche Conglomerate in the Xigaze Area, Southern Tibet: Implications for Himalayan Uplift and PaleoYarlung-Zangbo Initiation. J Geol, 121: 425-444

Wang J G, Hu X, Garzanti E, An W, Liu X C. 2017. The birth of the Xigaze forearc basin in southern Tibet. Earth Planet Sci Lett, 465: $38-47$
Wen D, Liu D, Chung S, Chu M, Ji J, Zhang Q, Song B, Lee T, Yeh M, Lo C. 2008. Zircon SHRIMP U-Pb ages of the Gangdese Batholith and implications for Neotethyan subduction in southern Tibet. Chem Geol, 252: 191-201

Wu F Y, Ji W Q, Liu C Z, Chung S L. 2010. Detrital zircon U-Pb and Hf isotopic data from the Xigaze fore-arc basin: Constraints on Transhimalayan magmatic evolution in southern Tibet. Chem Geol, 271: $13-25$

Wu F Y, Ji W Q, Wang J G, Liu C Z, Chung S L, Clift P D. 2014. Zircon $\mathrm{U}-\mathrm{Pb}$ and $\mathrm{Hf}$ isotopic constraints on the onset time of IndiaAsia collision. Am J Sci, 314: 548-579

Zhu D C, Pan G T, Chung S L, Liao Z L, Wang L Q, Li G M. 2008. SHRIMP zircon age and geochemical constraints on the origin of Lower Jurassic volcanic rocks from the Yeba Formation, Southern Gangdese, South Tibet. Int Geol Rev, 50: 442-471

Zhu D C, Mo X X, Niu Y, Zhao Z D, Wang L Q, Liu Y S, Wu F Y. 2009. Geochemical investigation of Early Cretaceous igneous rocks along an east-west traverse throughout the central Lhasa Terrane, Tibet. Chem Geol, 268: 298-312

Zhu D C, Zhao Z D, Niu Y, Mo X X, Chung S L, Hou Z Q, Wang L Q, Wu F Y. 2011. The Lhasa Terrane: Record of a microcontinent and its histories of drift and growth. Earth Planet Sci Lett, 301: 241-255

Zhu D C, Zhao Z D, Niu Y, Dilek Y, Hou Z Q, Mo X X. 2013. The origin and pre-Cenozoic evolution of the Tibetan Plateau. Gondwana Res, 23: 1429-1454

Ziabrev S V, Aitchison J C, Abrajevitch A V, Badengzhu A V, Davis A M, Luo H. 2003. Precise radiolarian age constraints on the timing of ophiolite generation and sedimentation in the Dazhuqu terrane, Yarlung-Tsangpo suture zone, Tibet. J Geol Soc, 160: 591-599

(责任编委: 丁林) 